\title{
Putative Effector Genes Distinguish Two Pathogenicity Groups of Fusarium oxysporum f. sp. spinaciae
}

\author{
Alexander M. Batson, ${ }^{1,+}$ Like Fokkens, ${ }^{2}$ Martijn Rep, ${ }^{2}$ and Lindsey J. du Toit ${ }^{1}$ \\ ${ }^{1}$ Washington State University Northwestern Washington Research and Extension Center Mount Vernon, Mount Vernon, WA \\ 98273, U.S.A. \\ ${ }^{2}$ Molecular Plant Pathology, Swammerdam Institute for Life Sciences, University of Amsterdam, Netherlands \\ Accepted 23 October 2020.
}

Fusarium wilt of spinach, caused by Fusarium oxysporum f. sp. spinaciae, is an important disease during warm conditions in production regions with acid soils, yet little is known about what confers pathogenicity to spinach in $F$. oxysporum f. sp. spinaciae genetically. To identify candidate fungal genes that contribute to spinach Fusarium wilt, each of 69 geographically diverse $\boldsymbol{F}$. oxysporum isolates was tested for pathogenicity on each of three spinach inbreds. Thirty-nine isolates identified as F. oxysporum f. sp. spinaciae caused quantitative differences in disease severity among the inbreds that revealed two distinct pathogenicity groups of $F$. oxysporum $f$. sp. spinaciae. Putative effector gene profiles, predicted from whole-genome sequences generated for nine $F$. oxysporum $\mathrm{f}$. $\mathrm{sp}$. spinaciae isolates and five nonpathogenic, spinach-associated $F$. oxysporum (NPS) isolates, distinguished the $F$. oxysporum f. sp. spinaciae isolates from the NPS isolates, and separated the $F$. oxysporum f. sp. spinaciae isolates into two groups. Five of the putative effector genes appeared to be unique to $F$. oxysporum $f$. sp. spinaciae, as they were not found in 222 other publicly available genome assemblies of $F$. oxysporum, implicating potential involvement of these genes in pathogenicity to spinach. In addition, two combinations of the 14 known Secreted in Xylem (SIX) genes that have been affiliated with host pathogenicity in other formae speciales of $F$. oxysporum were identified in genome assemblies of the nine $F$. oxysporum $\mathrm{f}$. sp. spinaciae isolates, either SIX 8 and SIXY or SIX4, SIX8, and SIX14. Characterization of these putative effector genes should aid in understanding mechanisms of pathogenicity in $F$. oxysporum f. sp. spinaciae, developing

The sequence reads of the 14 isolates of $F$. oxysporum were deposited in the sequence read archive (SRA) under the BioProject numbers PRJNA540981 and PRJNA595149. The corresponding assemblies were deposited in the NCBI GenBank repository.

${ }^{\dagger}$ Corresponding author: A. M. Batson; alex.batson@wsu.edu

Funding: The authors appreciate financial contributions from the Puget Sound Seed Growers' Association, the Richard and Marcia Morrison Seed Production Pathology Fellowship, the Robert MacDonald Graduate Student Fellowship, the Washington State Commission on Pesticide Registration (18AN016), and Agricultural, Human, and Natural Resource Sciences, Washington State University College Hatch Projects Nos. WNP0010 and WNP00595.

*The $\boldsymbol{e}$-Xtra logo stands for "electronic extra" and indicates supplementary material is published online.

The author(s) declare no conflict of interest.

Copyright $\odot 2021$ The Author(s). This is an open access article distributed under the CC BY 4.0 International license. molecular tools for rapid detection and quantification of $F$. oxysporum f. sp. spinaciae, and breeding for resistance to Fusarium wilt in spinach.

Keywords: fungal effectors, Fusarium wilt, Spinacia oleracea

The demand for spinach (Spinacia oleracea L.) in the United States has increased dramatically since the mid-1980s, when prepackaged and triple-rinsed baby leaf spinach became readily accessible to consumers (United States Department of Agriculture Economic Research Service 2007). This market demand for baby leaf spinach that is harvested 20 to 45 days after seeding crops at populations of 6 to 9 million seeds per hectare, necessitated an increase in production of high-quality spinach seed. High-quality spinach seed can be produced only in a few locations around the globe that have the long summer day length necessary to trigger spinach plants to bolt (convert from vegetative to reproductive growth), mild temperatures for this heat-sensitive species, and low humidity and rainfall during seed maturation for optimal seed quality and seed health (Metzger and Zeevaart 1985). The maritime Pacific Northwest (PNW) region of western Oregon and western Washington is the only region in the United States that meets these stringent climatic requirements to produce commercial spinach seed (Foss and Jones 2005; Organic Seed Alliance 2007). As a result, production of spinach seed in the maritime PNW accounts for up to $20 \%$ of the total global supply of spinach seed (Foss and Jones 2005).

Despite the optimal climatic conditions for spinach seed production in the maritime PNW, the acidic soils in this region are highly conducive to spinach Fusarium wilt, caused by Fusarium oxysporum f. sp. spinaciae (Foss and Jones 2005; Gatch and du Toit 2015). In these soils, F. oxysporum f. sp. spinaciae readily persists in excess of 10 years in the absence of spinach crops, which necessitates spinach seed producers use extensive crop rotations 10 to $15+$ years between spinach seed crops to avoid significant losses to the pathogen (du Toit and Ocamb 2019). In some fields, spinach seed crop rotations $>15$ years still have been insufficient to avoid losses of up to $100 \%$ (Gatch 2013). Historically, growers in the maritime PNW have avoided Fusarium wilt by planting spinach seed crops on land that had not previously been planted with spinach; however, land without a history of spinach or spinach seed production in this region is rare after about 100 years of spinach seed production (Gatch 2013). For fields with some risk of spinach Fusarium wilt, seed growers have used multiple practices to minimize losses to the disease, but all the economically viable management practices suppress the disease only partially or 
transiently or both (du Toit et al. 2004, 2006, 2014; Gatch and du Toit 2015, 2017). Spinach cultivars with partial resistance to Fusarium wilt are available, but most are highly susceptible to the disease (Laguna 2000; O'Brien and Winters 1977). Additionally, spinach seed growers typically have little or no choice of the proprietary inbred lines they are contracted to plant for hybrid seed crops. Therefore, additional management strategies are needed to reduce losses to Fusarium wilt and improve spinach seed yields in the United States.

F. oxysporum is a diverse species complex comprised of isolates that are nonpathogenic saprobes, biocontrol agents (Alabouvette et al. 2009), endophytes (Gordon and Martyn 1997), human pathogens (Nucci and Anaissie 2002), and plant pathogens. Plant-pathogenic isolates of $F$. oxysporum are grouped into $\geq 106$ host-specific formae speciales (EdelHermann and Lecomte 2019), each of which cause disease on a single host or, in some cases, a narrow range of closely related hosts (Armstrong and Armstrong 1976; Cafri et al. 2005; MacDonald and Leach 1976; Naiki and Kano 1977; Zhou and Everts 2007). Efforts to discriminate among $F$. oxysporum $\mathrm{ff}$. spp. and to differentiate isolates of formae speciales from nonpathogenic $F$. oxysporum isolates on the basis of morphological characteristics have fallen short, as these isolates typically are indistinguishable (Leslie and Summerell 2006). Furthermore, many $F$. oxysporum $\mathrm{ff}$. spp. are polyphyletic and cannot be differentiated based on multilocus DNA sequence haplotypes or DNA sequence variation among orthologous genes and noncoding loci (Baayen et al. 2000; Laurence et al. 2014; Lombard et al. 2019; Maryani et al. 2019; O'Donnell et al. 2009). Thus, time-consuming and labor-intensive pathogenicity tests have remained the standard for identification of isolates of many F. oxysporum ff. spp. (Leslie and Summerell 2006).

Advances in next generation sequencing and genomic studies of various $F$. oxysporum ff. spp. have improved our conceptual understanding of genetic similarities among formae speciales (Armitage et al. 2018; Ma et al. 2010; van Dam et al. 2016, 2017). Whole-genome sequencing of several closely related Fusarium spp. revealed that $F$. oxysporum f. sp. lycopersici, the causal agent of Fusarium wilt of tomato, has a genome of 59.9 $\mathrm{Mb}$, while $F$. graminearum, $F$. solani, and $F$. verticillioides have genomes of 36.2, 54.0, and $41.7 \mathrm{Mb}$, respectively (Coleman et al. 2009; Ma et al. 2010). The larger genome of F. oxysporum f. sp. lycopersici is due, primarily, to the presence of four lineage-specific chromosomes that are distinct from 11 core chromosomes (Ma et al. 2010). The core genome includes chromosomes that are syntenic among $F$. graminearum, $F$. solani, and $F$. verticillioides. In contrast, accessory or lineage-specific chromosomes are typically highly repetitive, transposon-rich, and encode genes associated with pathogenicity and host-specificity (Ma et al. 2010; Schmidt et al. 2013; van Dam et al. 2017; Williams et al. 2016). Furthermore, the transfer of one lineage-specific chromosome, chromosome 14 , from $F$. oxysporum f. sp. lycopersici to a nonpathogenic $F$. oxysporum isolate converted that recipient isolate to a pathogen of tomato (Ma et al. 2010). This phenomenon of horizontal chromosome transfer conferring host-specificity has also been demonstrated between F. oxysporum f. sp. radicis-cucumerinum and a nonpathogen of cucurbits (Li et al. 2020; van Dam et al. 2017).

Accessory chromosomes of $F$. oxysporum f. sp. lycopersici contain a group of 14 genes known as Secreted in Xylem (SIX) genes, which are expressed as proteins that are secreted by $F$. oxysporum f. sp. lycopersici into the xylem of colonized tomato plants (Rep 2005; Rep et al. 2004; Schmidt et al. 2013). These proteins are relatively small ( $<300$ amino acids) and rich in cysteine residues (Schmidt et al. 2013). Deletion of SIX1
(Rep 2005), SIX3 (Houterman et al. 2009), SIX5 (Ma et al. 2015), and SIX6 (Gawehns et al. 2014) from isolates of F. oxysporum f. sp. lycopersici reduced virulence of the isolates to tomato, demonstrating the role of these genes in pathogenicity of the fungus. Furthermore, the three known races of F. oxysporum f. sp. lycopersici are differentiated by SIX1, SIX3, and SIX4, each of which is an avirulence gene (also referred to as $A V R 3, A V R 2$, and $A V R 1$, respectively) (Houterman et al. 2008, 2009; Rep et al. 2004). SIX1, SIX3, and SIX4 encode proteins that are detected by resistance proteins in certain tomato cultivars, encoded by immunity $(I)$ genes. The $I$ genes that correspond to SIX1, SIX3, and SIX4 in F. oxysporum f. sp. lycopersici were discovered among wild Solanum relatives of tomato (Gerdemann and Finley 1951; McGrath et al. 1987) and have been introgressed into commercial breeding lines of tomato to confer resistance to the three races of $F$. oxysporum $\mathrm{f}$. sp. lycopersici (Catanzariti et al. 2015; Simons et al. 1998).

Subsequent to the discovery and characterization of the SIX genes in $F$. oxysporum f. sp. lycopersici, many other formae speciales of $F$. oxysporum have been demonstrated to have homologs of SIX genes, e.g., ff. spp. canariensis, cepae, ciceris, conglutinans, cubense, fragariae, lini, melonis, niveum, palmarum, physali, pisi, radicis-cucumerinum, raphani, vasinfectum, and zingiberri (Czislowski et al. 2018; Laurence et al. 2015; Lievens et al. 2009; Meldrum et al. 2012; Ponukumati et al. 2019; Simbaqueba et al. 2018; Taylor et al. 2016; Thatcher et al. 2012; van Dam et al. 2016; Williams et al. 2016). Lievens et al. (2009) first demonstrated that the profile of SIX genes could potentially be used to differentiate among isolates of different $F$. oxysporum ff. spp. as well as to distinguish isolates of formae speciales from nonpathogenic isolates. Furthermore, Taylor et al. (2016) demonstrated that SIX3, SIX5, SIX7, SIX9, SIX10, SIX12, and SIX14 were all present in highly virulent isolates of $F$. oxysporum f. sp. cepae, the causal agent of Fusarium basal rot of onion, while isolates with diminished virulence to onion had fewer of these $S I X$ genes. The profiles of SIX genes present in $F$. oxysporum f. sp. cepae isolates differentiated the pathogenic isolates from nonpathogenic isolates of F. oxysporum associated with onion plants and differentiated isolates of this forma specialis from those of eight other formae speciales evaluated in that study. Similarly, Czislowski et al. (2018) demonstrated that SIX gene profiles in isolates of the causal agent of Fusarium wilt of banana, F. oxysporum f. sp. cubense, were associated strongly with different races and vegetative compatibility groups (VCG) of the pathogen. The SIX genes also have been demonstrated to play a role in virulence of $F$. oxysporum $\mathrm{f}$. sp. cubense to banana (Widinugraheni et al. 2018) and for the causal agent of Fusarium wilt of Brassica spp., F. oxysporum f. sp. conglutinans (Thatcher et al. 2012).

In comparison with other $F$. oxysporum ff. spp., the genetics behind host specificity and pathogenicity in $F$. oxysporum $\mathrm{f}$. sp. spinaciae have not been studied extensively. Fiely et al. (1995) demonstrated three VCGs present among $F$. oxysporum f. sp. spinaciae isolates collected from a variety of geographic locations. Subsequently, F. oxysporum f. sp. spinaciae was found to be polyphyletic with respect to two loci, the translation elongation factor 1- $\alpha$ (TEF1- $\alpha)$ gene and the intergenic spacer (IGS) region of ribosomal DNA (rDNA). Based on these two regions, representative isolates of $F$. oxysporum $\mathrm{f}$. sp. spinaciae in VCGs 0330 and 0332 grouped together, while an isolate belonging to VCG 0331 was placed in a separate clade (O'Donnell et al. 2009). A few studies have included F. oxysporum f. sp. spinaciae isolates in screens for SIX genes, but $F$. oxysporum f. sp. spinaciae isolates were not the main focus of those investigations. For example, Lievens et al. (2009) included three $F$. oxysporum $\mathrm{f}$. $\mathrm{sp}$. spinaciae isolates in a genotypic screen for SIX1 to SIX7 of 255 isolates representing 16 
formae speciales and 15 nonpathogenic $F$. oxysporum isolates. None of these SIX genes was detected in the three $F$. oxysporum f. sp. spinaciae isolates. At that time, only SIX1 to SIX7 had been identified. Later, Covey et al. (2014) screened isolates of F. oxysporum ff. spp. betae and spinaciae for SIX1, SIX6, and other loci. Neither SIX1 nor SIX6 was detected in the three F. oxysporum f. sp. spinaciae isolates evaluated.

Analysis of the genomic locations of SIX1 to SIX7 on lineage-specific chromosome 14 of $F$. oxysporum f. sp. lycopersici revealed that these effector genes were associated with transposable elements, i.e., a miniature inverted-repeat transposable element (MITE) in the $5^{\prime}$ promoter region called a miniature Impala (mimp) (Schmidt et al. 2013). The association of mimps with the promoter region of each of the SIX genes facilitated the discovery of SIX9 to SIX14 (Schmidt et al. 2013), and, subsequently, mimps were used as markers to discover other putative effector genes in other $F$. oxysporum ff. spp. (Armitage et al. 2018; Schmidt et al. 2016; van Dam et al. 2016). The presence or absence of SIX genes and mimppredicted effector genes has been used to differentiate some $F$. oxysporum ff. spp. and even to differentiate among races of specific formae speciales (Czislowski et al. 2018; Lievens et al. 2009; Taylor et al. 2016; van Dam et al. 2016), which holds promise for the potential development of molecular tools that can discriminate isolates of different formae speciales. van Dam et al. (2016) demonstrated that $F$. oxysporum ff. spp. cucumerinum, niveum, melonis, radicis-cucumerinum, and lycopersici were differentiated by the presence or absence of candidate effector genes. Isolates of $F$. oxysporum $\mathrm{ff}$. spp. that caused wilt of Cucurbitaceae genera and species (i.e., ff. spp. cucumerinum, melonis, niveum, and radicis-cucumerinum) had similar predicted effector gene profiles, suggesting that host specificity is determined by an isolate's repertoire of effector genes.

Identifying effector genes associated with $F$. oxysporum f. sp. spinaciae may provide insights into the molecular interactions between $F$. oxysporum f. sp. spinaciae and spinach. In addition, identifying genes that play a putative role in pathogenicity will enable development of molecular tools to differentiate isolates of the pathogen rapidly and aid spinach breeders in developing cultivars with resistance to Fusarium wilt. The goal of this research was to determine the potential genetic basis of pathogenicity of the causal agent of spinach Fusarium wilt, F. oxysporum f. sp. spinaciae, through identifying putative effector genes in this pathogen.

\section{RESULTS}

\section{Distinct patterns of virulence differentiate two pathogenicity groups of $F$. oxysporum f. sp. spinaciae.}

To identify $F$. oxysporum isolates pathogenic on spinach, pathogenicity trials were conducted with 69 isolates collected from multiple locations, plant hosts, substrates, and years (Supplementary Table S1). Fifty of the F. oxysporum isolates had been associated with wilting spinach plants, soil in which spinach crops were grown, or spinach seed. Each of the remaining $19 F$. oxysporum isolates were derived from other host substrates and were confirmed by the respective supplier as pathogenic isolates of $F$. oxysporum $\mathrm{ff}$. spp. betae (beet), cepae (onion), ciceris (chickpea), and pisi (pea) (Supplementary Table S1). Each isolate was tested for pathogenicity on each of three proprietary spinach inbred lines (coded A, B, and C) that have been described as highly susceptible, moderately susceptible, or partially resistant to spinach Fusarium wilt, respectively (Gatch and du Toit 2015). Therefore, the wilt response was predicted to be quantitative. Inbred A was expected to display the most severe symptoms of wilt, followed by $\mathrm{B}$, and then $\mathrm{C}$. Although three inbreds were tested in these trials, inbreds $\mathrm{A}$ and $\mathrm{C}$ represented what were considered highly susceptible and partially resistant inbreds to Fusarium wilt, so only the wilt severity of inbreds $\mathrm{A}$ and $\mathrm{C}$ are presented in Figure 1, as these two inbreds showed the greatest differentiation among fungal isolates. The number of treatment combinations of spinach inbred lines and isolates was prohibitively large to assess in a single trial, so isolates were assessed for pathogenicity over six trials.

Thirty-six of the 69 isolates caused symptoms of Fusarium wilt on at least one of the three spinach inbred lines evaluated (Fig. 1) that were significantly greater than that of the control plants treated with water $(P<0.05)$. None of the isolates tested in trials 5 and 6 caused spinach plants to wilt, so the results are not shown. Isolate Fus254, the positive control isolate, caused the most severe wilt observed on inbred $\mathrm{A}$ in each trial. The negative control isolate Fus 187 did not cause wilt in any of the trials. In trials 1 to 4 , the severity of wilt differed among fungal isolates $(P<0.0001$ for the analysis of variance [ANOVA] main effect of isolates) and among inbred lines $(P<0.0001)$. In addition, the interaction of inbred lines and fungal isolates was significant in each trial $(P \leq 0.0295)$. Two distinct patterns of virulence were observed among the $F$. oxysporum f. sp. spinaciae isolates (Fig. 1). The $17(45 \%)$ isolates that induced the most severe wilt symptoms on inbred A were placed in pathogenicity group $1(P<0.05)$ and $19(50 \%)$ isolates that either induced similarly severe wilt symptoms on all three inbred lines $(P \geq 0.05)$ or the most severe symptoms on inbred $\mathrm{C}(P<0.05)$ were assigned to pathogenicity group 2 (Fig. 1; Supplementary Table S1). Two isolates, Fus 172 and Fus287, induced such mild symptoms of wilt that they could not be placed in either group. Of the $30 \mathrm{Fusarium}$ isolates tested that did not induce wilt symptoms on the spinach inbreds, 11 were collected originally from wilting spinach plants, spinach seed, or soil in which spinach had been grown and were identified as NPS isolates (Supplementary Table S1). The remaining 19 Fusarium isolates belonged to other $F$. oxysporum ff. spp. and did not cause wilt symptoms on the spinach inbreds.

Seven $F$. oxysporum f. sp. spinaciae isolates and five NPS isolates were tested again on spinach inbreds $\mathrm{A}$ and $\mathrm{C}$ in preparation for selecting isolates for whole-genome sequencing. The $F$. oxysporum f. sp. spinaciae isolates selected based on diversity of geographic origin, year of isolation, and the severity of wilt induced on the three inbred spinach lines included Fus057, Fus059, Fus254, and Fus322, representing pathogenicity group 1, and Fus167 and Fus173, representing pathogenicity group 2. Although Fus001 did not induce wilting of spinach plants in the initial pathogenicity tests, this isolate had been demonstrated previously to be a pathogen of spinach (Okubara et al. 2013), so the isolate was included in this additional testing. Five NPS isolates (Fus017, Fus187, Fus191, Fus250, and Fus259) were selected based on the lack of virulence to spinach in the initial pathogenicity trials as well as diversity in the years in which the isolates were collected. Pathogenicity tests with these 12 isolates were performed twice on both inbreds A and C. Similar to results of the initial pathogenicity trials (Fig. 1), a differential interaction between spinach inbreds and fungal isolates was observed (Table 1; Supplementary Figs. S1 and S2), with the isolates distinguished into the same two pathogenicity groups based on quantitative differences in wilt severity on inbreds A and C (Table 1). Isolates identified as nonpathogenic on spinach (NPS isolates Fus017, Fus187, Fus191, Fus250, and Fus259) in the initial pathogenicity tests did not induce either of the spinach inbreds to wilt (Table 1; Supplementary Fig. S2). Fus001 caused a greater severity of wilt on inbred $\mathrm{C}$ than $\mathrm{A}$ in trial 1 but caused a similar severity of wilt on the two spinach inbreds in trial 2 , 
similar to the other group 2 isolates Fus167 and Fus173 (Table 1). Thus, Fus001 was assigned to pathogenicity group 2 (Table 1; Supplementary Figs. S1 and S2).

\section{F. oxysporum f. sp. spinaciae isolates are monophyletic based on TEF1- $\alpha$.}

Phylogenetic relationships among the $F$. oxysporum f. sp. spinaciae isolates were inferred based on sequence alignment of the TEF1- $\alpha$ locus from the 69 isolates included in the pathogenicity tests described above. Despite the diverse geographic origins and years in which the $F$. oxysporum $\mathrm{f}$. sp. spinaciae isolates were collected, all $39 F$. oxysporum f. sp. spinaciae isolates had identical sequences for this locus and grouped in one moderately supported clade $(71 \%$ bootstrap support [Fig. 2]). Only one NPS isolate, Fus263, clustered with the $F$. oxysporum f. sp. spinaciae isolates. The other 10 NPS isolates were dispersed throughout the phylogenetic tree and were more closely related to isolates of other $F$. oxysporum ff. spp. than to $F$. oxysporum f. sp. spinaciae (Fig. 2). The isolates of $F$. oxysporum ff. spp. ciceris and cepae tested were monophyletic, whereas the isolates of $F$. oxysporum ff. spp. lycopersici and pisi were polyphyletic (Fig. 2). Some isolates did not group within the $F$. oxysporum species complex. For example, NPS isolate Fus317 was identified as a member of the F. fujikuroi species complex (Fig. 2). Moreover, of the nine isolates classified by the original supplier as $F$. oxysporum $\mathrm{f}$. sp. betae, only two were identified as $F$. oxysporum based on the TEF $1-\alpha$ sequences. The other seven were identified as F. equiseti $(n=1)$ or unknown Fusarium spp. $(n=6)$ (Fig. 2).
Whole-genome assemblies of $\boldsymbol{F}$. oxysporum $\mathrm{f}$. sp. spinaciae were larger and more fragmented than those of NPS isolates.

To evaluate genetic differences among $F$. oxysporum f. sp. spinaciae isolates in pathogenicity group 1, group 2, and NPS isolates, 14 isolates were selected for whole-genome sequencing, including all 12 isolates subjected to the additional pathogenicity tests described above. The genome of isolate Fus167 was sequenced twice, once by each of two institutions, resulting in two genome assemblies for the same isolate named Fus167vA and Fus167vB (Table 2). To obtain a higher-quality reference genome, the well-characterized isolate Fus 254 (pathogenicity group 1) was sequenced with the Pacific Biosciences (PacBio) Sequel platform (Menlo Park, CA, U.S.A.), while the other 13 isolates were sequenced with Illumina technology.

The genome assemblies generated from Illumina paired-end reads of the nine $F$. oxysporum f. sp. spinaciae isolates and five NPS isolates ranged from 47.6 to $56.7 \mathrm{Mbp}$ (Table 2) and were assembled into 387 to 4,042 contigs. Overall, the $F$. oxysporum f. sp. spinaciae assemblies generated with Illumina data were more fragmented (2,696 to 4,042 contigs) and larger (54.7 to $56.7 \mathrm{Mbp}$ ) than the genome assemblies of the NPS isolates generated with Illumina data (387 to 1,518 contigs and 47.6 to $51.4 \mathrm{Mbp}$ ) (Table 2). Of the Illumina-generated genome assemblies, the $F$. oxysporum f. sp. spinaciae group 1 assemblies were more fragmented and approximately $300 \mathrm{Kbp}$ smaller, on average, than the $F$. oxysporum f. sp. spinaciae group 2 assemblies (Table 2). In comparison, the Fus254 (F. oxysporum $\mathrm{f}$.

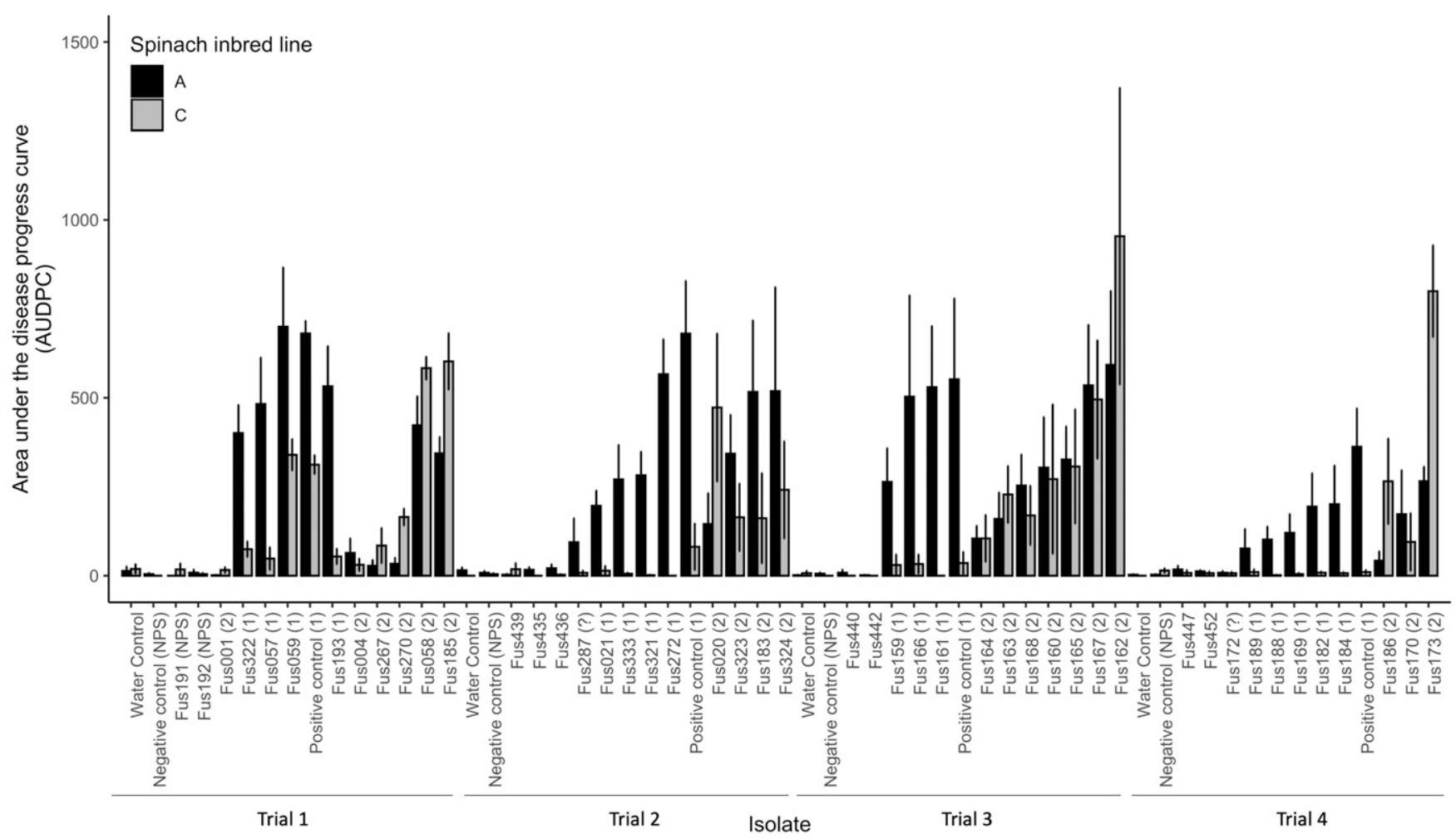

Fig. 1. Mean \pm standard error of the area under the disease progress curve for four replications of each of 49 Fusarium isolates characterized for pathogenicity on each of the two proprietary spinach inbred lines A and C. Results for four of the six pathogenicity trials are shown since none of the isolates of $F$. oxysporum ff. spp. and other $F$. oxysporum associated with spinach that were tested in trials 5 and 6 was pathogenic on spinach. Each trial included a positive control isolate (Fus254) of F. oxysporum f. sp. spinaciae, a negative control isolate of F. oxysporum that is not pathogenic on spinach (Fus187), and a water control treatment. Numbers or characters in parentheses following each isolate indicate the designation of a $F$. oxysporum f. sp. spinaciae pathogenicity group (i.e., $1=$ group $1,2=$ group $2, ?=$ no group designation) or whether the isolate was determined to be nonpathogenic on spinach but associated originally with spinach (NPS). 
Table 1. Analysis of variance (ANOVA) testing the effects of spinach inbred line and isolate of Fusarium oxysporum on the area under the disease progress curve (AUDPC) ${ }^{\mathrm{x}}$

\begin{tabular}{|c|c|c|c|c|}
\hline \multirow{3}{*}{$\begin{array}{l}\text { ANOVA } \\
\text { factor }^{y}\end{array}$} & \multicolumn{4}{|c|}{$\mathbf{A U D P C}^{\mathbf{z}}$} \\
\hline & \multicolumn{2}{|c|}{ Trial 1} & \multicolumn{2}{|c|}{ Trial 2} \\
\hline & Inbred A & Inbred C & Inbred A & Inbred C \\
\hline Fus057 & $1,681.25 \mathrm{a}$ & $242.71 \mathrm{f}$ & $1,684.67 \mathrm{a}$ & $281.75 \mathrm{e}$ \\
\hline Fus059 & $1,556.46 \mathrm{a}$ & 395.83 ef & $1,751.46 \mathrm{a}$ & $699.71 \mathrm{~cd}$ \\
\hline Fus254 & $848.38 \mathrm{bc}$ & $192.71 \mathrm{f}$ & $1,705.08 \mathrm{a}$ & $660.33 \mathrm{cde}$ \\
\hline Fus322 & $1,210.21 \mathrm{ab}$ & $201.46 \mathrm{f}$ & $548.92 \mathrm{de}$ & $88.96 \mathrm{f}$ \\
\hline Fus001 & $430.21 \mathrm{def}$ & $851.46 \mathrm{bc}$ & $1,165.79 \mathrm{~b}$ & $1,066.92 \mathrm{~b}$ \\
\hline Fus167 & $230.42 \mathrm{f}$ & 628.92 cde & $1,163.75 \mathrm{~b}$ & $1,222.96 \mathrm{~b}$ \\
\hline Fus173 & $708.33 \mathrm{~cd}$ & $1,154.79 \mathrm{ab}$ & $697.96 \mathrm{~cd}$ & $953.75 \mathrm{bc}$ \\
\hline Fus017 & 4.79 ghij & $7.71 \mathrm{hij}$ & $0.00 \mathrm{~g}$ & $7.29 \mathrm{~g}$ \\
\hline Fus187 & $1.04 \mathrm{j}$ & 6.25 ghij & $0.00 \mathrm{~g}$ & $14.58 \mathrm{~g}$ \\
\hline Fus191 & $10.83 \mathrm{gh}$ & $1.04 \mathrm{j}$ & $0.00 \mathrm{~g}$ & $87.50 \mathrm{~g}$ \\
\hline Fus250 & $26.50 \mathrm{~g}$ & $0.00 \mathrm{j}$ & $0.00 \mathrm{~g}$ & $5.83 \mathrm{~g}$ \\
\hline Fus259 & 59.38 ghi & $0.00 \mathrm{j}$ & $2.92 \mathrm{~g}$ & $0.00 \mathrm{~g}$ \\
\hline Water & $0.00 \mathrm{j}$ & $2.08 \mathrm{ij}$ & $0.00 \mathrm{~g}$ & $0.00 \mathrm{~g}$ \\
\hline
\end{tabular}

${ }^{\mathrm{x}}$ Results of ANOVA testing the effects of spinach inbred line and isolate of $F$ oxysporum on the AUDPC assessed in two trials in which spinach plants were grown in potting medium inoculated with each isolate to identify isolates of the spinach Fusarium wilt pathogen $F$. oxysporum f. sp. spinaciae

${ }^{y}$ Each value is the mean of four replications. The experiment in both trials was a randomized complete block layout of a factorial treatment design of two spinach inbred lines and 13 inoculation treatments. The main effects of spinach inbred line and inoculation treatment as well as the interaction term were significant in both trials. Raw data were either log- or rank-transformed due to heterogeneity of variances or nonnormal residuals or both. Within each trial, means with at least one letter in common are not different statistically, based on Fisher's protected least significant difference $(P<0.05)$

${ }^{\mathrm{z}}$ AUDPC based on wilt severity ratings completed weekly from 14 to 35 days after planting. sp. spinaciae group 1) PacBio assembly was $56.3 \mathrm{Mbp}$ divided over 279 contigs. Each genome assembly was similar in terms of the percentage of complete single-copy orthologs identified with the BUSCO (benchmarking universal single-copy orthologs) program (Simão et al. 2015), which ranged from $98.8 \%$, for the PacBio assembly of Fus254, to $99.2 \%$ (3,680 to 3,695 BUSCOs) (Table 2). This indicated that, although fragmented, the genome assemblies were largely complete.

\section{Phylogenomic analysis of $F$. oxysporum f. sp. spinaciae isolates distinguished the two pathogenicity groups.}

To determine the relationship of the $F$. oxysporum $\mathrm{f}$. $\mathrm{sp}$. spinaciae and NPS isolates to other $F$. oxysporum isolates with publicly available genome assemblies, single-copy orthologs $(n=3,127)$ identified with BUSCO (Simão et al. 2015) were used to infer gene trees for constructing a summary tree with the program ASTRAL-III (Zhang et al. 2018). The genome assemblies of the $F$. oxysporum f. sp. spinaciae isolates, five NPS isolates, and 13 other $F$. oxysporum isolates evaluated in this study were grouped into three lineages that were well supported by the percentage of quartet trees $(>70 \%)$ and local posterior probabilities (Fig. 3). The phylogenetic relationships of genomes of the other $F$. oxysporum ff. spp. were similar to those described in other studies (Armitage et al. 2018; van Dam et al. 2016). The nine $F$. oxysporum f. sp. spinaciae isolates sequenced in this study occupied two closely related but distinct lineages (Fig. 3). The node supporting F. oxysporum f. sp. spinaciae group 1 isolates was present in $52.8 \%$ of the quartet trees (1,651 quartet trees), and the node supporting $F$. oxysporum $\mathrm{f}$. sp. spinaciae group 2 isolates was present in $58.4 \%$ of the quartet trees (1,826 quartet trees) (Fig. 3). Isolates assigned

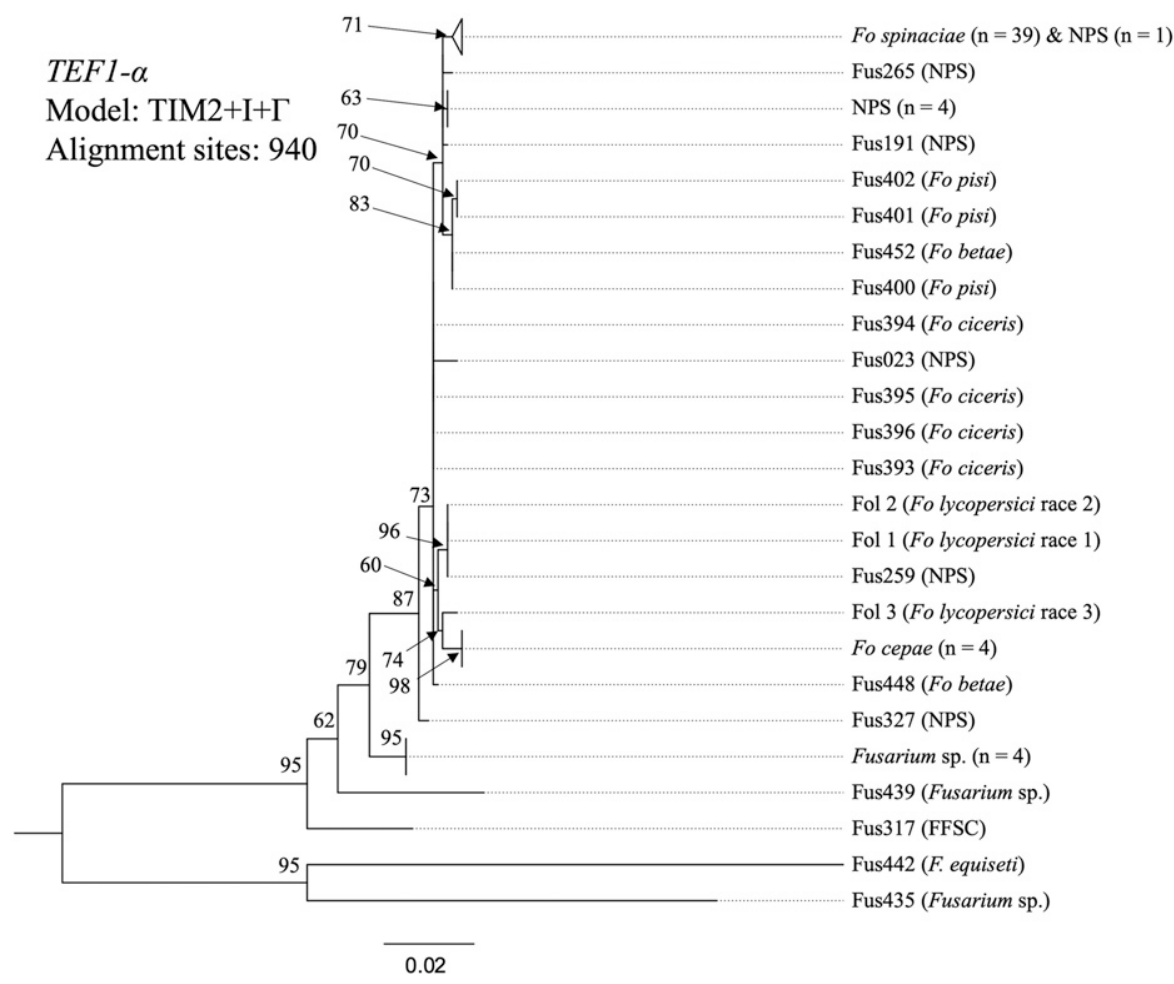

Fig. 2. Unrooted maximum likelihood tree inferred for translation elongation factor 1- $\alpha$ (TEF1- $\alpha$ ) sequences of Fusarium isolates subjected to pathogenicity tests, on two spinach inbred lines, to identify isolates of $F$. oxysporum $\mathrm{f}$. sp. spinaciae, the causal agent of spinach Fusarium wilt. The number at each node represents the percentage of trees from 1,000 bootstrap replicates with that node. The scale bar indicates the average number of substitutions per site. $F o=$ Fusarium oxysporum, NPS $=$ nonpathogenic, spinach-associated $F$. oxysporum isolate, $\mathrm{FFSC}=F$. fujikuroi species complex isolate. Values in parentheses refer to the number of isolates within a collapsed, monophyletic clade. 
to $F$. oxysporum f. sp. spinaciae group 1 shared a more recent common ancestor with a representative isolate of $F$. oxysporum f. sp. vasinfectum, a pathogen of cotton, than with isolates of F. oxysporum f. sp. spinaciae group 2 , with that ancestor represented by $40.2 \%$ of the quartet trees $(1,257$ quartet trees).
Additionally, the five NPS isolates were more closely related to each other at these loci than to any of the F. oxysporum $\mathrm{f}$. sp. spinaciae isolates evaluated. Two isolates of $F$. oxysporum $\mathrm{f}$. sp. cubense tropical race 4 included in this tree, i.e., isolates Foc4 and Fo_II5, were described recently as a new species,

Table 2. Assembly statistics of 15 Fusarium oxysporum genomes for identification of putative effectors that define the spinach Fusarium wilt pathogen $F$. oxysporum f. sp. spinaciae

\begin{tabular}{|c|c|c|c|c|c|c|c|}
\hline Assemblyu & Designation $^{v}$ & No. of contigs & $\begin{array}{l}\text { Total length } \\
\text { (Mbp) }\end{array}$ & $\begin{array}{c}\text { Largest } \\
\text { contig (Kbp) }\end{array}$ & N50 $(K b p)^{w}$ & $\mathbf{L 5 0}^{\mathbf{x}}$ & $\begin{array}{c}\text { Complete } \\
\text { BUSCOs }(\%)^{y}\end{array}$ \\
\hline Fus254 (JAALGI000000000) & Group 1 & 279 & 56.3 & $1,713.9$ & 625.5 & 28 & 98.8 \\
\hline Fus057 (JAALGR000000000) & Group 1 & 4,042 & 56.2 & 690.3 & 94.4 & 140 & 99.1 \\
\hline Fus059 (JAALGQ000000000) & Group 1 & 4,007 & 56.1 & $1,028.0$ & 94.4 & 142 & 99.0 \\
\hline Fus166 (JABCQY000000000) & Group 1 & 2,993 & 54.7 & $1,680.6$ & 137.5 & 77 & 99.1 \\
\hline Fus322 (JAALGJ000000000) & Group 1 & 4,003 & 56.1 & 601.9 & 92.8 & 149 & 99.1 \\
\hline Fus001 (JAALGT000000000) & Group 2 & 3,098 & 56.2 & $1,383.9$ & 156.6 & 85 & 99.2 \\
\hline Fus165 (JABCQZ000000000) & Group 2 & 2,841 & 55.7 & $1,638.4$ & 281.2 & 44 & 99.1 \\
\hline Fus167vA (JAALGP000000000) & Group 2 & 3,748 & 56.7 & 759.4 & 141.7 & 105 & 99.0 \\
\hline Fus167vB (JABCQX000000000) & Group 2 & 2,696 & 55.6 & $2,715.7$ & 316.7 & 43 & 99.0 \\
\hline Fus173 (JAALGO000000000) & Group 2 & 3,021 & 56.2 & 974.3 & 146.0 & 89 & 99.0 \\
\hline Fus017 (JAALGS000000000) & NPS & 1,518 & 51.4 & $1,168.8$ & 255.0 & 56 & 98.9 \\
\hline Fus187 (JAALGN000000000) & NPS & 998 & 49.2 & $1,307.7$ & 239.4 & 57 & 99.0 \\
\hline Fus191 (JAALGM000000000) & NPS & 387 & 47.6 & $1,263.7$ & 329.9 & 42 & 99.1 \\
\hline Fus250 (JAALGL000000000) & NPS & 1,139 & 50.1 & $1,132.4$ & 277.9 & 49 & 99.1 \\
\hline Fus259 (JAALGK000000000) & NPS & 821 & 49.3 & $1,115.9$ & 308.4 & 45 & 99.1 \\
\hline
\end{tabular}

u Name and GenBank accession number of the genome assembly. The PacBio Sequel sequencing platform was used to generate read data for Fus254; the Illumina HiSeq platform was used for all the others.

v Designated as either Fusarium oxysporum f. sp. spinaciae pathogenicity group 1 or group 2 or as NPS for F. oxysporum isolates that were not pathogenic on spinach although originally obtained from a spinach plant, spinach seed, or soil in which spinach was grown. Pathogenicity groups are isolates that induced differential severity of wilt symptoms on two spinach inbred lines.

${ }^{\mathrm{w}} \mathrm{N} 50=$ the median contig length in a genome assembly, i.e., the length of the shortest contig among the minimum number of contigs in an assembly whose summed length is $\geq 50 \%$ of the length of the genome assembly.

${ }^{x} \mathrm{~L} 50=$ the minimum number of contigs whose summed length is $\geq 50 \%$ of the length of the genome assembly.

y Percentage of single copy orthologs in a genome as assessed with the BUSCO program (Simão et al. 2015).

$\mathrm{z}$ The genome assemblies for Fus167vA and Fus167vB were generated from the same isolate, Fus 167.

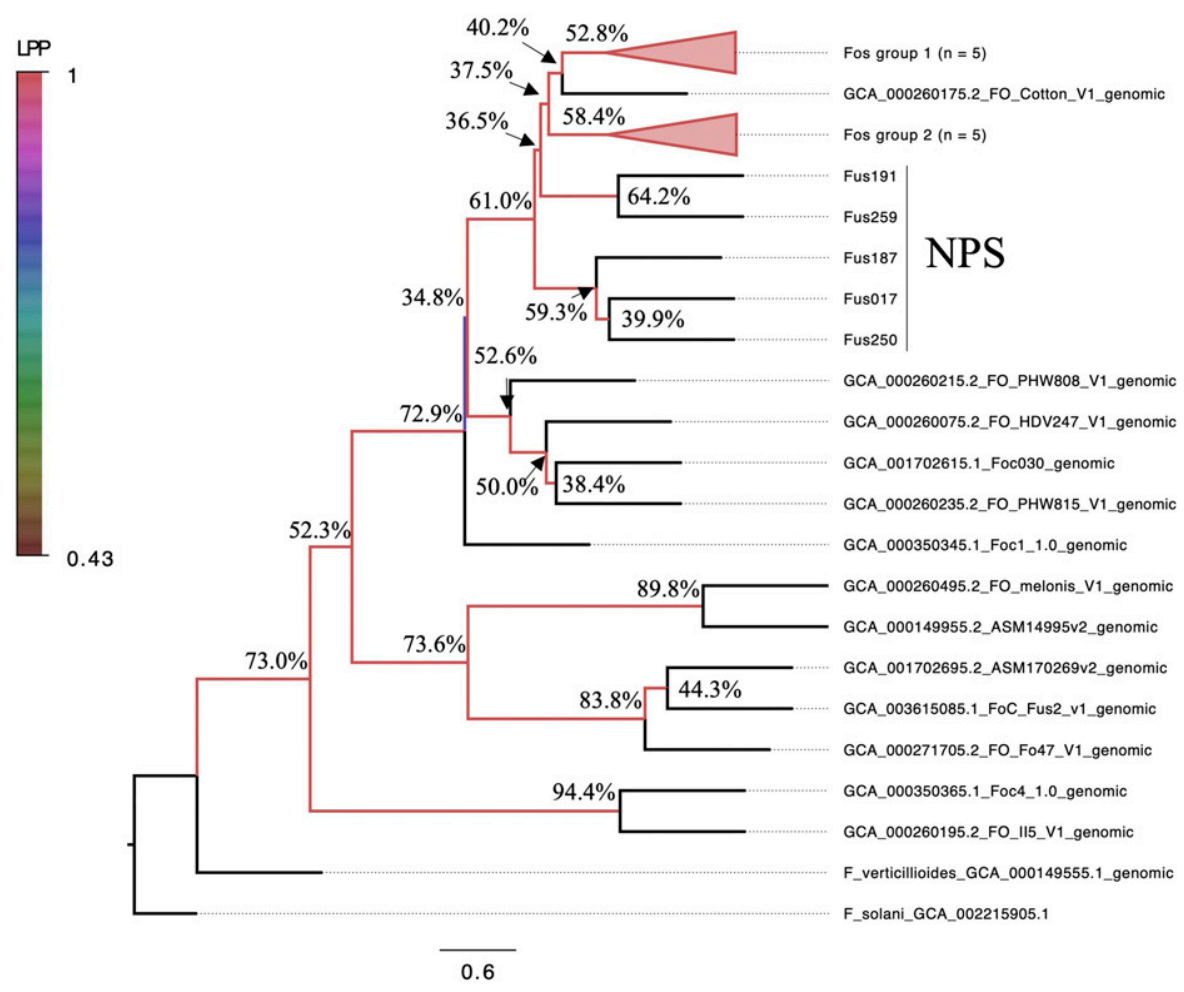

Fig. 3. Phylogenetic tree demonstrating the relationship among 28 Fusarium oxysporum isolates, one F. verticillioides isolate, and one F. solani isolate. The tree was inferred from 3,127 single-copy ortholog-gene trees present in each Fusarium genome assembly, using the program ASTRAL-III. Fos = F. oxysporum f. sp. spinaciae (pathogenicity group), NPS $=F$. oxysporum isolate that was not a pathogen on spinach but was obtained originally from a spinach plant, spinach seed, or soil in which spinach was grown. The two $F$. oxysporum f. sp. spinaciae pathogenicity groups were based on isolates that induced differential severity of wilt on two spinach inbred lines. Colored branches indicate node support based on local posterior probabilities (LPPs), while the percentages adjacent to the nodes indicate the quartet support. The scale bar indicates coalescence units. The final tree was rooted to F. solani. 
F. odoratissimum (Lombard et al. 2019; Maryani et al. 2019), and represented a clade distinct from the other $F$. oxysporum isolates with $94.4 \%$ quartet support and $100 \%$ bootstrap support on the concatenated tree (Fig. 3; Supplementary Fig. S1).

There were minor topological discrepancies between the ASTRAL-inferred tree and the tree inferred from a concatenated alignment of 3,127 BUSCOs (Fig. 3; Supplementary Fig. S3). In both trees, the five NPS isolates belonged to one of two clades; however, the relationship of the NPS clades to F. oxysporum f. sp. spinaciae isolates differed slightly between the trees (Fig. 3; Supplementary Fig. S3). In both trees, the nodes that supported the different placements had relatively low support, either $36.5 \%$ of quartet tree support in the ASTRAL-inferred tree or $56 \%$ bootstrap support in the concatenated phylogeny (Supplementary Fig. S3). In addition, the relationship between $F$. oxysporum f. sp. cucumerinum isolate Foc030 (GCA_001702615.1) and F. oxysporum isolates HDV247 (GCA_000260075.2) and PHW815 (GCA_000260235.2) differed between the two trees (Fig. 3; Supplementary Fig. S3). However, in both trees, the relationship among $F$. oxysporum f. sp. spinaciae group 1 isolates, $F$. oxysporum f. sp. spinaciae group 2 isolates, a F. oxysporum f. sp. vasinfectum isolate (GCA_ 000260175.2 ), and other recognized clades of $F$. oxysporum isolates was congruent.

\section{Homology searches identify putative effectors in $\boldsymbol{F}$. oxysporum f. sp. spinaciae.}

The 14 known SIX gene homologs in $F$. oxysporum $\mathrm{f}$. sp. lycopersici were queried against each of the $F$. oxysporum $\mathrm{f}$. sp. spinaciae and NPS genome assemblies with the command line tool BLASTN. Two combinations of SIX genes were identified in the $10 \mathrm{~F}$. oxysporum $\mathrm{f}$. sp. spinaciae genome assemblies, SIX8 and SIX9 or SIX4, SIX8, and SIXI4 (Table 3). The genome assemblies of all five $F$. oxysporum $\mathrm{f}$. sp. spinaciae group 1 isolates (Fus057, Fus059, Fus166, Fus254, and Fus322) had homologs of SIX4, SIX8, and SIX14 whereas the five genome assemblies of the four isolates of $F$. oxysporum $\mathrm{f}$. sp. spinaciae group 2 (Fus001, Fus165, Fus167vA, Fus167vB, and Fus173) had SIX8 and SIX9 (Table 3). Only one of the five NPS isolates, Fus187, had a complete copy of SIX14. No other SIX genes were detected in the five NPS genome assemblies (Table 3). The SIX4, SIX8, and SIX14 DNA sequences of F. oxysporum $\mathrm{f}$. sp. spinaciae group 1 isolates were 85,87 , and $92 \%$ identical, respectively, to the equivalent $S I X$ homologs in F. oxysporum $\mathrm{f}$. sp. lycopersici. A 217-bp insertion was detected in the SIX9 homolog of $F$. oxysporum f. sp. spinaciae group 2 isolates which, when translated in-frame, resulted in a premature stop codon in the hypothetical protein (data not shown). Two copies of SIX8 were identified in the genome assemblies of all F. oxysporum f. sp. spinaciae group 2 isolates, with approximately $80 \%$ DNA sequence identity to each other. Interestingly, one of the copies of SIX8 in the genome assemblies of $F$. oxysporum f. sp. spinaciae group 2 isolates was identical to that of the SIX 8 homolog found in the genome assemblies of the five $F$. oxysporum f. sp. spinaciae group 1 isolates, while the other copy of $S I X 8$ in the $F$. oxysporum $\mathrm{f}$. sp. spinaciae group 2 isolates had $91 \%$ DNA sequence identity to that of F. oxysporum f. sp. lycopersici.

Three copies of SIX14 were identified in the PacBio assembly of Fus254 (Table 3). Two of the three copies were identical. The third copy had a single insertion of a cytosine residue at base pair 64, which, when translated, would result in a premature stop codon (data not shown). A complete copy of SIX14 could not be extracted from the genome assemblies of F. oxysporum f. sp. spinaciae group 1 isolates Fus057, Fus059, and Fus322, as the gene was only assembled partially for those assemblies, i.e., the first 63 base pairs of the gene were present at the end of a contig. The gene was assembled improperly at the same base pair where a cytosine insertion was observed in one copy of SIX14 in the PacBio assembly of Fus 254.

\section{Putative effector gene profiles differentiate \\ F. oxysporum f. sp. spinaciae and NPS isolates.}

A pipeline that identifies mimp-associated effector genes (van Dam et al. 2016) was used to predict putative effector genes in the $F$. oxysporum f. sp. spinaciae and NPS genome assemblies. In total, 52 putative effector genes were predicted, and the effector gene profiles of the $F$. oxysporum f. sp. spinaciae isolates and NPS isolates differentiated the isolates into three distinct groups, i.e., F. oxysporum f. sp. spinaciae group 1 isolates, $F$. oxysporum f. sp. spinaciae group 2 isolates, and NPS isolates (Fig. 4). Twenty-two of the mimp-associated genes were predicted among all the $F$. oxysporum f. sp. spinaciae isolates as well as the NPS isolates, suggesting that these genes are likely associated with the core genome of $F$. oxysporum isolates associated with spinach. Twelve predicted genes were specific to the $10 \mathrm{~F}$. oxysporum f. sp. spinaciae genome assemblies representing nine $F$. oxysporum $\mathrm{f}$. sp. spinaciae isolates (Fig. 4). An additional five effector genes were specific to the assemblies of all five $F$. oxysporum f. sp. spinaciae group 2 isolates (Fig. 4). Homologs of SIX4, SIX8, $S I X 9$, and SIX14 were detected using this pipeline (Fig. 4). However, a SIX14-like homolog was identified in all of the genome assemblies of the $F$. oxysporum $\mathrm{f}$. sp. spinaciae group 2 isolates, the NPS isolate Fus187, and two $F$. oxysporum f. sp. spinaciae group 1 isolates (Fus166 and Fus254), even though this gene was not detected in these same genome assemblies (Table 3).

Table 3. Presence or absence profile of homologs of the 14 known Secreted in Xylem (SIX) genes from Fusarium oxysporum $\mathrm{f}$. sp. lycopersici identified in the genome assemblies of $10 \mathrm{~F}$. oxysporum $\mathrm{f}$. sp. spinaciae isolates and five $F$. oxysporum isolates that were not pathogenic on spinach but were associated originally with spinach

\begin{tabular}{lcccccc}
\hline & & \multicolumn{5}{c}{ Secreted in Xylem $\left(\right.$ SIX) genes $^{\mathbf{y}}$} \\
\cline { 3 - 7 } Isolate & Designation $^{\mathbf{x}}$ & SIX4 & SIX8a & SIX8b & SIX9 & SIXI4 \\
\hline Fus057 & Group 1 & $+(1)$ & - & $+(1)$ & - & $+(1)$ \\
Fus059 & Group 1 & $+(1)$ & - & $+(1)$ & - & $+(1)$ \\
Fus166 & Group 1 & $+(1)$ & - & $+(1)$ & - & $+(1)$ \\
Fus254 & Group 1 & $+(1)$ & - & $+(1)$ & - & $+(3)$ \\
Fus322 & Group 1 & $+(1)$ & - & $+(1)$ & - & $+(1)$ \\
Fus001 & Group 2 & - & $+(1)$ & $+(1)$ & $+(1)$ & - \\
Fus165 & Group 2 & - & $+(1)$ & $+(1)$ & $+(1)$ & - \\
Fus167vA & Group 2 & - & $+(1)$ & $+(1)$ & $+(1)$ & - \\
Fus167vB & Group 2 & - & $+(1)$ & $+(1)$ & $+(1)$ & - \\
Fus173 & Group 2 & - & $+(1)$ & $+(1)$ & $+(1)$ & - \\
Fus017 & NPS & - & - & - & - & - \\
Fus187 & NPS & - & - & - & - & $+(1)$ \\
Fus191 & NPS & - & - & - & - & - \\
Fus250 & NPS & - & - & - & - & - \\
Fus259 & NPS & - & - & - & - & - \\
\hline
\end{tabular}

${ }^{\mathrm{x}}$ Isolates were identified as Fusarium oxysporum $\mathrm{f}$. sp. spinaciae pathogenicity groups 1 or 2 or NPS. Pathogenicity groups are based on $F$. oxysporum $\mathrm{f}$. sp. spinaciae isolates that induced differential severity of wilt on two spinach inbred lines. NPS means the F. oxysporum isolate was not pathogenic on spinach although it was obtained originally from a spinach plant, spinach seed, or soil in which spinach was grown.

y The presence of a SIX gene homolog is indicated by + and the absence of a $S I X$ gene homolog is indicated by -. Numbers in parentheses represent the copy number of the $S I X$ gene homolog identified by a BLASTN search with default parameters or by mapping Illumina reads with Bowtie 2 (Langmead and Salzberg 2012). SIX1 to SIX3, SIX5 to SIX7, and SIX10 to SIX13 were not detected in any of the $F$. oxysporum $\mathrm{f}$. sp. spinaciae or NPS genome assemblies.

${ }^{\mathrm{z}}$ Genome assemblies Fus167vA and Fus167vB were generated from the same isolate, Fus 167. 
When submitted to a BLASTX search against the nonredundant protein sequence database, $30(58 \%)$ of the mimpassociated genes coded for hypothetical proteins reported in the genomes of other F. oxysporum isolates or Fusarium spp., or the predicted genes did not resemble any BLASTX annotated genes. The remaining 22 genes coded for predicted peptides that were homologous to various secretory carbohydratedegrading enzymes, kinases, nucleotide-binding transcription factors, and the SIX genes. When the 52 effector genes predicted were queried against other publicly available $F$. oxysporum genome assemblies $(n=222)$, four were found exclusively in the $F$. oxysporum f. sp. spinaciae isolates of both pathogenicity groups (MLFRPLWLPWRRLLKSLACGTFQTP VCA, MIYMVVALLGTMQCVC, MLCSFMLLLYLSIITNC, and MLISSSLTWLSLAYLGAA) and one was found only in the genomes of $F$. oxysporum $\mathrm{f}$. sp. spinaciae group 2 isolates (MVGTIIIMAAFVGLA).

MLFRPLWLPWRRLLKSLACGTFQTPVCA was the only F. oxysporum f. sp. spinaciae effector that was $100 \%$ identical for all nine $F$. oxysporum f. sp. spinaciae isolates. When the DNA and amino acid sequences of the putative effector gene MIYMVVALLGTMQCVC were compared, two haplotypes were found. Eight isolates (Fus001, Fus057, Fus059, Fus165, Fus166, Fus173, Fus254, and Fus322) had identical DNA and amino acid sequences at this locus, while this homolog in the two genome assemblies for isolate Fus 167 differed from that of the other isolates at four DNA base pairs or two amino acids. Similarly, two haplotypes of MLCSFMLLLYLSIITNC were found in the assemblies of all the $F$. oxysporum f. sp. spinaciae isolates. Eight isolates (Fus001, Fus057, Fus059, Fus165, Fus166, Fus173, Fus254, and Fus322) had identical DNA and amino acid sequences at this locus, which encode a valid peptide. However, the MLCSFMLLLYLSIITNC homolog identified in both assemblies of isolate Fus167 lacked 29 bp in the DNA alignment, which introduced a premature stop codon in the predicted translation. These three putative effector genes had no similarity to proteins in the InterPro database. The fourth gene found in the $F$. oxysporum $\mathrm{f}$. sp. spinaciae genome assemblies, MLISSSLTWLSLAYLGAA, was not assembled completely for Fus057, Fus059, and Fus322 in F. oxysporum $\mathrm{f}$. sp. spinaciae group 1. However, the partial DNA sequences of this effector in these assemblies were $100 \%$ identical to that of the other two $F$. oxysporum f. sp. spinaciae group 1 isolates, Fus166 and Fus254. Two copies of MLISSSLTWLSLAYLGAA

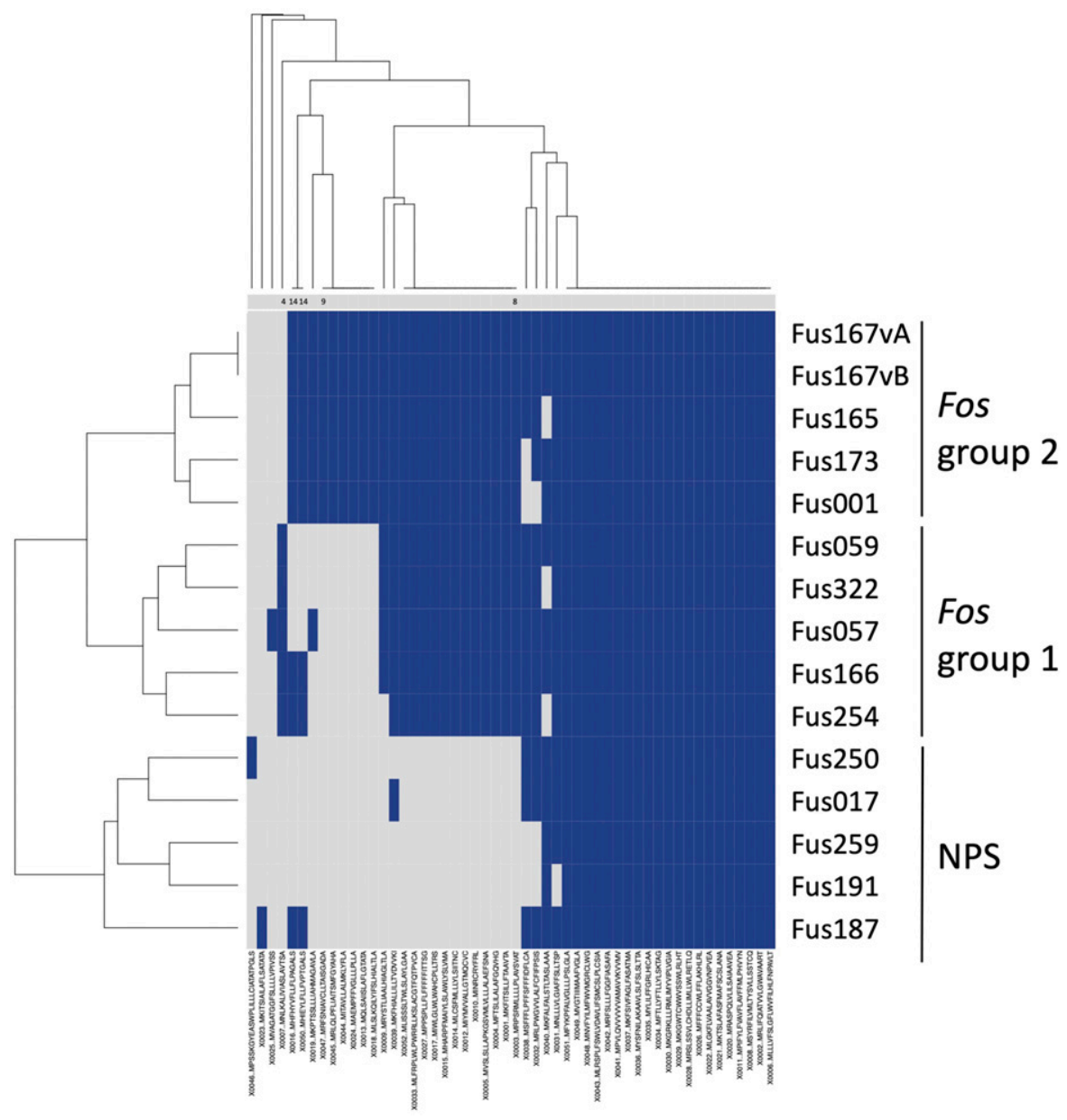

Fig. 4. Presence or absence plot of putative effector genes found in Fusarium oxysporum f. sp. spinaciae (Fos) isolates in comparison with nonpathogenic isolates of $F$. oxysporum associated with spinach (NPS isolates), divided into two pathogenicity groups of isolates that induced differential symptoms of wilt on spinach inbred lines and a group of nonpathogenic, spinach-associated $F$. oxysporum isolates (NPS). Putative effector genes were identified using the pipeline developed by van Dam et al. (2016). Open reading frames (ORFs) were identified within 2,000 base pairs downstream of a miniature impala transposable element that had characteristics of effector genes. Individual ORFs were each selected as a putative effector gene if the putative peptide had a predicted signal peptide (assessed with SignalP 4.0) and the number of amino acids was between 25 and 600. Solid blue boxes indicate the presence of an ORF in a genome assembly, while shaded gray boxes indicate the absence of an ORF. The genome assemblies (rows) are clustered hierarchically by putative effector profile (left $y$ axis), and the putative effector genes (columns) are clustered by distribution within each assembly (top $x$ axis). Numbers at the top of columns represent the putative effector genes homologous to one of the 14 known Secreted in Xylem (SIX) genes (e.g., 4 represents SIX4, 8 represents $S I X 8)$. The genome assemblies Fus167vA and Fus167vB were generated from the same isolate, Fus167. 
were found in isolates Fus059 and Fus254, which differed at two base-pair positions and resulted in two synonymous amino acid substitutions in the predicted peptide. The predicted protein encoded by MLISSSLTWLSLAYLGAA had similarity to proteins with extracellular carbohydrate (mannan) hydrolase activity. The putative effector gene MVGTIIIMAAFVGLA was only detected in the assemblies of $F$. oxysporum $\mathrm{f}$. sp. spinaciae group 2 genome assemblies (Fig. 4). This putative effector gene and the predicted peptide were $100 \%$ identical for the F. oxysporum f. sp. spinaciae group 2 isolates. The predicted protein had gene ontology terms implicating kinase activity, proton-exporting ATPase activity, plasma membrane localization, and positive regulation of the target of rapamycin complex 1 (TORC1) signaling.

\section{Comparison of the genomes of}

\section{F. oxysporum f. sp. lycopersici isolate 4287 and}

$F$. oxysporum f. sp. spinaciae isolate Fus254.

A comparison of the genomes of $F$. oxysporum f. sp. spinaciae isolate Fus 254 and $F$. oxysporum f. sp. lycopersici isolate 4287 revealed the presence or absence of core and lineagespecific regions in both genomes (Fig. 5). Chromosomes 3, 6, $11,12,13,14$, and 15 in $F$. oxysporum $\mathrm{f}$. sp. lycopersici isolate 4287 shared few or none of the single-copy BUSCOs common among Sordariomycetes with the genome assembly of $F$. oxysporum f. sp. spinaciae isolate Fus254 (Fig. 5). As demonstrated in previous studies (Ma et al. 2010; Schmidt et al. 2013), chromosome 14, a pathogenicity chromosome in $F$. oxysporum f. sp. lycopersici, harbors SIX1 to SIX3 and SIX5 to SIX14 (Fig. 5). As expected, this chromosome was also enriched with mimps (85 single-stranded mimp motifs). The genome assembly of Fus 254 was highly partitioned. All of the SIX genes and nearly all the $F$. oxysporum $\mathrm{f}$. sp. spinaciae-predicted effector genes identified in the genome assemblies of Fus 254 and this race 2 isolate of $F$. oxysporum $\mathrm{f}$. sp. lycopersici were present in genomic regions separate from the BUSCOs (Fig. 5).

\section{DISCUSSION}

The main objective of this study was to identify the putative genetic basis of pathogenicity of $F$. oxysporum f. sp. spinaciae. In this study, for the first time, putative effector genes were predicted from whole-genome assemblies of F. oxysporum $\mathrm{f}$. sp. spinaciae isolates, which lead to the discovery of five candidate effector genes uniquely associated with $F$. oxysporum f. sp. spinaciae. The presence or absence profile of the effector genes identified through a homology search or by $a b$ initio prediction downstream of mimps facilitated the differentiation of $F$. oxysporum f. sp. spinaciae isolates from $F$. oxysporum isolates that were not pathogens of spinach. Although the function of these $F$. oxysporum f. sp. spinaciae-specific putative effector genes remains unknown, their identification provides an

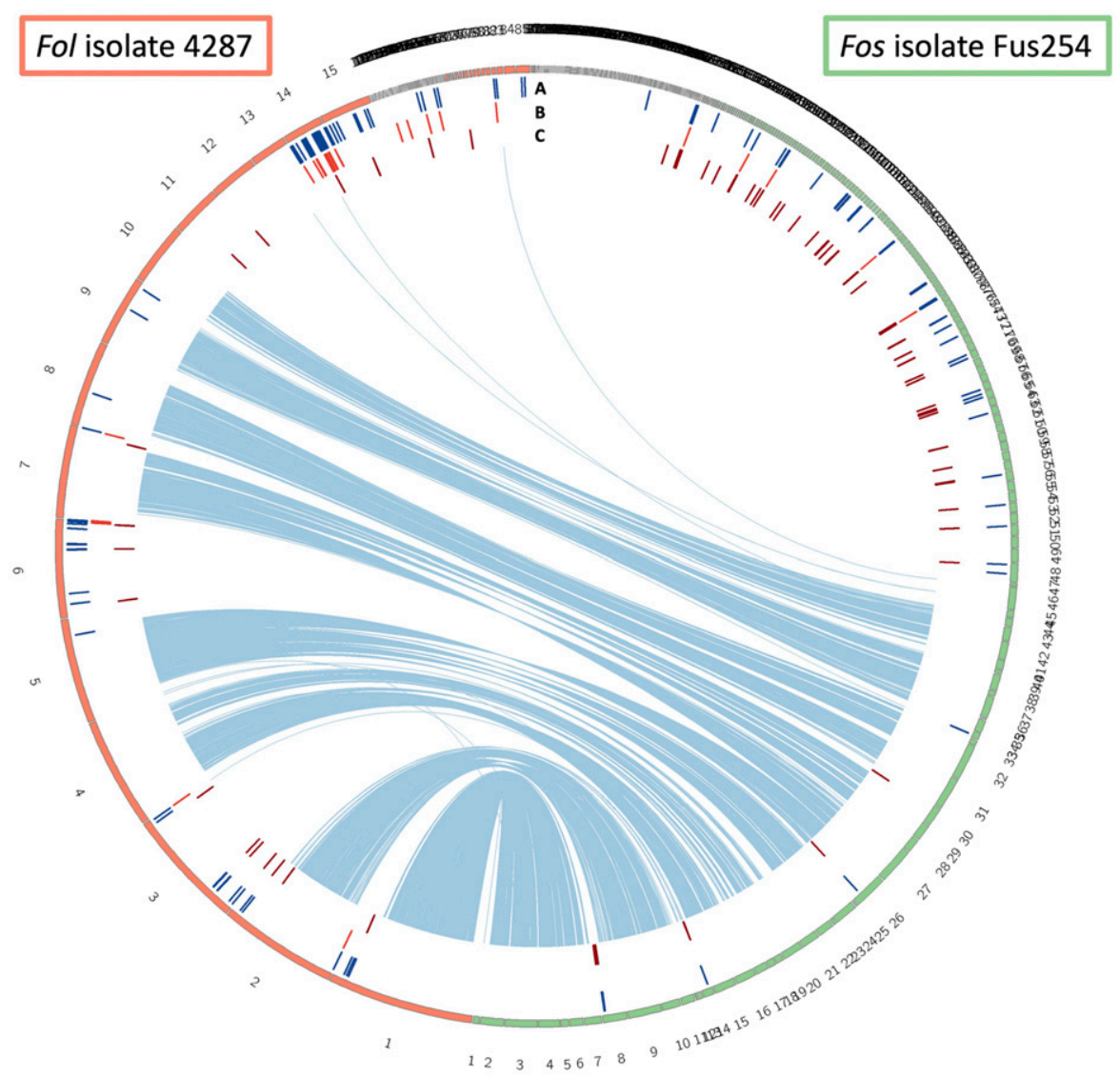

Fig. 5. Organization and comparison of genome assemblies of Fusarium oxysporum f. sp. lycopersici (Fol) isolate 4287 (GenBank accession GCA_000149955.2) (red) and F. oxysporum f. sp. spinaciae (Fos) isolate Fus254 (green). Boxes and numbers at the outer edge of the circle represent chromosomes (F. oxysporum f. sp. lycopersici) or contigs (F. oxysporum f. sp. spinaciae) and chromosome or contig number, respectively. A, Miniature impala motifs are highlighted in dark blue; B, the location of Secreted in Xylem genes are highlighted in light red; and $\mathbf{C}$, the location of putative effector genes identified with the pipeline used in this study are noted in maroon. The putative effectors (C) were searched for in the assemblies of $F$. oxysporum $\mathrm{f}$. sp. spinaciae isolate Fus254 and $F$. oxysporum f. sp. lycopersici isolate 4287. Light blue lines that connect contigs of $F$. oxysporum f. sp. lycopersici and $F$. oxysporum f. sp. spinaciae each represent the position of one single-copy, orthologous gene out of 3,533 total genes identified with the BUSCO program (Simão et al. 2015) and the ortholog dataset for Sordariomycete orthologs (dataset odb9). 
invaluable foundation for determining the genetic basis of pathogenicity and host specificity of the causal agent of spinach Fusarium wilt. In addition to identification of putative effector genes, the $F$. oxysporum f. sp. spinaciae isolates evaluated in this study were differentiated into two distinct pathogenicity groups based on quantitative differences in wilt severity between two spinach inbreds. Isolates of the two $F$. oxysporum $\mathrm{f}$. sp. spinaciae groups could be differentiated from each other based on group-specific profiles of candidate effector genes, which may contribute to the differences in wilt severity that F. oxysporum f. sp. spinaciae group 1 and group 2 isolates induced on the two spinach inbreds.

Of the Fusarium isolates confirmed as $F$. oxysporum f. sp. spinaciae by inoculation of spinach inbred lines, all but two exhibited differential virulence on two of the three spinach inbreds evaluated. This discriminated the $F$. oxysporum f. sp. spinaciae isolates into two pathogenicity groups. Although quantitative differences in virulence among $F$. oxysporum f. sp. spinaciae isolates have been demonstrated (Fiely et al. 1995) as well as quantitative differences in susceptibility of spinach cultivars to $F$. oxysporum f. sp. spinaciae (Laguna 2000; O'Brien and Winters 1977), the distinct differential susceptibility of spinach cultivars to isolates of $F$. oxysporum $\mathrm{f}$. sp. spinaciae observed in this study has not been described previously. Interestingly, two races of $F$. oxysporum f. sp. spinaciae were proposed by Armstrong and Armstrong (1976); however, those races were based on the observation that some F. oxysporum f. sp. spinaciae isolates induced wilt on spinach and beet, Beta vulgaris subsp. vulgaris, which they called race 1 isolates, whereas other isolates only induced wilt on beet, which they called race 2 isolates. This race designation proposed by Armstrong and Armstrong (1976) was not associated with differential severity of wilt caused by the isolates on spinach cultivars but on host specificity to different genera of plants. In this study, F. oxysporum $\mathrm{f}$. sp. spinaciae isolates were assigned to two pathogenicity groups rather than races, since pathogenic races defined for other $F$. oxysporum ff. spp. have been based on differences in susceptibility of cultivars within a host species (Edel-Hermann and Lecomte 2019; Gordon and Martyn 1997; Kistler 1997). In this study, the F. oxysporum $\mathrm{f}$. sp. spinaciae isolates evaluated induced wilt on all three spinach inbred lines tested, but the severity of wilt differed quantitatively between two inbred lines, with isolates of F. oxysporum $\mathrm{f}$. sp. spinaciae group 1 causing more severe wilt on spinach inbred $\mathrm{A}$ than inbred $\mathrm{C}$, whereas isolates of F. oxysporum f. sp. spinaciae group 2 caused more severe wilt on inbred $\mathrm{C}$ than inbred A. Naming the two F. oxysporum $\mathrm{f}$. sp. spinaciae groups as races could be misinterpreted to convey solely qualitative differences in susceptibility of spinach lines to isolates of the two pathogenicity groups.

Quantitative differences in virulence detected among isolates of $F$. oxysporum f. sp. spinaciae within the same pathogenicity group, and quantitative differences between isolates from the two pathogenicity groups identified in this study may reflect genetic loci that confer different degrees of virulence on specific spinach cultivars. For example, $F$. oxysporum f. sp. spinaciae isolate Fus267 induced more severe wilt on spinach inbred lines $\mathrm{B}$ and $\mathrm{C}$ than on inbred $\mathrm{A}$, and Fus058 induced even more severe wilt on inbred $\mathrm{C}$ than did Fus267. Generating whole-genome sequences of $F$. oxysporum f. sp. spinaciae isolates from the same pathogenicity group that demonstrated different levels of virulence on spinach (such as Fus267 and Fus058) could be valuable for identifying effector genes or genomic regions that influence pathogenicity quantitatively. Based on prior studies (Gatch and du Toit 2015), two of the three inbred spinach inbred lines used in this study to identify $F$. oxysporum f. sp. spinaciae isolates coincidentally differentiated a large majority of the $F$. oxysporum f. sp. spinaciae isolates into the two pathogenicity groups. Additional patterns of virulence among $F$. oxysporum f. sp. spinaciae isolates might potentially be identified by testing $F$. oxysporum f. sp. spinaciae isolates for pathogenicity on more diverse spinach germplasm (Batson et al. 2020; Gyawali et al. 2019).

Although Fusarium wilt can be a devastating disease of spinach and is the most important limitation for spinach seed production in the United States (Foss and Jones 2005), little is known about the genetic basis of pathogenicity of $F$. oxysporum f. sp. spinaciae. Similar to other host-specific $F$. oxysporum isolates that have been demonstrated to have unique profiles of effector genes, this study demonstrated a distinct association of isolates of the two $F$. oxysporum f. sp. spinaciae pathogenicity groups with candidate effector gene profiles identified by whole-genome sequencing of $F$. oxysporum $\mathrm{f}$. sp. spinaciae isolates and NPS isolates. In addition, the presence or absence profiles of these candidate effector genes differentiated the F. oxysporum f. sp. spinaciae isolates into the same two groups defined by the pathogenicity tests on two spinach inbreds. Four of the 52 candidate effector genes were unique to the F. oxysporum f. sp. spinaciae isolates compared with all other publicly available $F$. oxysporum genome assemblies, and one putative effector gene was unique to isolates of $F$. oxysporum $\mathrm{f}$. sp. spinaciae pathogenicity group 2 .

The 14 known SIX genes discovered in F. oxysporum f. sp. lycopersici and used to profile other $F$. oxysporum ff. spp. (Czislowski et al. 2018; Lievens et al. 2009; Ponukumati et al. 2019; Taylor et al. 2016) were investigated in this study for the potential to profile $F$. oxysporum $\mathrm{f}$. sp. spinaciae isolates. The results demonstrated, for the first time, that homologs of SIX4, SIX8, SIX9, or SIX14, singly or in combination, are present in $F$. oxysporum f. sp. spinaciae genomes. Furthermore, isolates of the two pathogenicity groups of $F$. oxysporum f. sp. spinaciae were differentiated by the presence or absence profile of the $S I X$ genes; SIX 8 and SIX9 were detected in all five F. oxysporum $\mathrm{f}$. sp. spinaciae group 2 isolates sequenced, while $S I X 4$, SIX8, and SIX14 were detected in the assemblies of all five $F$. oxysporum f. sp. spinaciae group 1 isolates sequenced. Interestingly, only one of the SIX genes, SIX14, also was found in the genome assemblies of one of five NPS isolates sequenced (Fus187). Other isolates of $F$. oxysporum not known to be pathogenic on any plant species have been demonstrated to have SIX genes (Deltour et al. 2018; Taylor et al. 2016; Tesdall et al. 2017; Rocha et al. 2016). Some isolates have even been shown to possess a profile of SIX genes that matched that of the tomato pathogen $F$. oxysporum f. sp. lycopersici (Jelinski et al. 2017). These observations suggest that the presence of specific SIX genes alone may not be a sufficient predictor of virulence in F. oxysporum ff. spp., i.e., other genetic factors may influence virulence on specific hosts, such as the presence of other effector genes or the regulation of transcription of the SIX genes.

The presence or absence of the putative effectors identified in this study distinguished $F$. oxysporum $\mathrm{f}$. sp. spinaciae and NPS isolates. Furthermore, the profile of candidate, mimp-predicted effector genes clearly distinguished isolates of $F$. oxysporum $\mathrm{f}$. sp. spinaciae group 1 from isolates of $F$. oxysporum f. sp. spinaciae group 2. This corroborated previous studies that found unique combinations of effector genes associated with certain F. oxysporum ff. spp. (Lievens et al. 2009; Taylor et al. 2016; Williams et al. 2016; van Dam et al. 2016). However, the roles of these putative effector genes as well as the SIX genes in hostspecificity of the $F$. oxysporum f. sp. spinaciae isolates to spinach are unknown. Some of the predicted functions of these genes are related to carbohydrate degradation, which may aid in breaking down plant cell-wall components, nutrient acquisition, or overcoming host defenses (de Jonge et al. 2010; 
Tonukari et al. 2000; van Esse et al. 2008). However, a majority of the mimp-predicted genes encoded hypothetical proteins or proteins without an inferred function, which may encode novel peptides involved in spinach $-F$. oxysporum $\mathrm{f}$. sp. spinaciae interactions. In addition, four of the predicted effector genes were unique to both $F$. oxysporum $\mathrm{f}$. sp. spinaciae groups compared with other $F$. oxysporum genome assemblies, and a fifth effector gene was present only in $F$. oxysporum f. sp. spinaciae group 2 isolates. Further studies are warranted for elucidating the functions of these putative effector genes, by determining whether these genes are expressed during infection of spinach and are required for virulence to spinach.

In this study, representative isolates of $F$. oxysporum $\mathrm{f}$. sp. spinaciae group 1 occupied a phylogenetic lineage that was closely related to but distinct from isolates of $F$. oxysporum $\mathrm{f}$. sp. spinaciae group 2. This is congruent with findings from O'Donnell et al. (2009), who separated three $F$. oxysporum f. sp. spinaciae isolates into two lineages. The three $F$. oxysporum $\mathrm{f}$. sp. spinaciae isolates evaluated by O'Donnell et al. (2009) had been characterized for pathogenicity to spinach by Fiely et al. (1995), who found that these isolates belonged to three different VCGs and isolates of the two lineages differed in the severity of wilt they induced on the spinach cultivar Grandstand. Interestingly, $F$. oxysporum f. sp. spinaciae group 1 isolates were more closely related to an isolate of $F$. oxysporum $\mathrm{f}$. sp. vasinfectum than to $F$. oxysporum $\mathrm{f}$. $\mathrm{sp}$. spinaciae group 2 isolates. This supports the notion that phylogenetic lineages of isolates of some formae speciales may be poor predictors of host-specificity, especially given that entire chromosomes that confer pathogenicity can potentially be transferred between isolates (Ma et al. 2010; Shahi et al. 2016; van Dam et al. 2017).

Molecular assays for rapid identification of isolates of specific F. oxysporum ff. spp. have been developed based on SIX genes (Carvalhais et al. 2019) as well as other putative effector genes identified through comparative genomics (van Dam et al. 2018). The unique DNA sequences of the $F$. oxysporum $\mathrm{f}$. sp. spinaciae homologs of the SIX genes and the $F$. oxysporum $\mathrm{f}$. sp. spinaciae-specific effector genes identified in this study indicate that these loci may be promising markers for development of one or more molecular diagnostic assays for F. oxysporum f. sp. spinaciae. An assay that enables rapid and cost-effective identification and, potentially, quantification of F. oxysporum f. sp. spinaciae in culture or in situ is needed in place of time- and resource-intensive pathogenicity tests. Although a real-time PCR assay was developed for detection of F. oxysporum f. sp. spinaciae based on a single nucleotide polymorphism in the IGS region of rDNA (Okubara et al. 2013), that test failed to discriminate isolates of $F$. oxysporum $\mathrm{f}$. sp. spinaciae from a majority of NPS isolates tested (70\% of NPS isolates cross-reacted with the assay) as well as isolates of a few other formae speciales. In the absence of a highly specific, sensitive, and quantitative molecular assay for $F$. oxysporum $\mathrm{f}$. sp. spinaciae, a soil bioassay has been used annually in the maritime PNW region of the United States since 2010 to quantify the risk of spinach Fusarium wilt in spinach seed growers' fields. Spinach seed of inbred lines that differ in susceptibility to Fusarium wilt are planted into soil sampled from each field, and symptoms of Fusarium wilt are rated over the course of seven weeks to quantify the risk of Fusarium wilt (Gatch and du Toit 2015). Although the soil bioassay is a highly effective, direct, and quantitative test for spinach Fusarium wilt risk that has been used effectively as a risk management tool for evaluating almost 500 fields over 10 years, the assay is laborintensive, not easily scalable, and requires a minimum of two months to yield results. This emphasizes the need to develop a molecular assay that provides growers with a rapid and costeffective response. Such an assay could be designed based on the putative effector genes identified in this study that differentiated isolates of $F$. oxysporum f. sp. spinaciae from NPS isolates. Furthermore, the assay could be designed based on the effector genes that differentiate $F$. oxysporum f. sp. spinaciae isolates of the two pathogenicity groups to reflect potential differences in risk based on genetic background of the spinach lines to be planted in a field (Batson et al. 2020). However, an advantage of the soil bioassay over a DNA-based molecular assay is that accurate quantification of the risk of a disease like Fusarium wilt is not determined solely by the number of propagules of the pathogen. Numerous other factors, such as soil $\mathrm{pH}$, competitive soil microflora, and soil micronutrient concentrations, can have a significant influence on disease pressure (Gatch and du Toit 2015; Malvick et al. 1994; Oyarzun et al. 1994) but would not be accounted for using a DNA-based assay.

\section{MATERIALS AND METHODS}

\section{Pathogenicity trials.}

Sixty-nine Fusarium oxysporum isolates were tested for pathogenicity on each of three proprietary spinach inbred lines, $\mathrm{A}, \mathrm{B}$, and $\mathrm{C}$. The isolates were tested in groups over a set of six trials due to space constraints. The number of unique F. oxysporum isolates tested in each trial ranged from 12 to 14 . The isolates tested in trials 5 and 6 were all expected to be nonpathogenic to spinach, based on information provided by the supplier of these isolates, except for the positive control isolate of $F$. oxysporum f. sp. spinaciae included in each trial, Fus254. For this reason and to accommodate space constraints, only inbred A was used in trial 6. Each pathogenicity test was conducted as a randomized complete block design with four replicate blocks of the factorial treatment combinations. In each trial, spinach plants were inoculated with $F$. oxysporum f. sp. spinaciae isolate Fus 254 as a positive control treatment. A spinach-associated $F$. oxysporum isolate that was not pathogenic on spinach but which originated from spinach (NPS isolate Fus187) served as one negative control treatment, and water was used as a second negative control treatment in each trial.

Spinach seeds of each inbred were planted in RediEarth propagation mix (SunGro Horticulture, Agawam, MA, U.S.A.) in 6-cell packs (TLC Polyform, Inc., Salem, OR, U.S.A.). The seedlings were maintained in a greenhouse or a growth chamber, depending on the time of year, with a 9-h day, 15-h night diurnal cycle, to prevent bolting, at $22^{\circ} \mathrm{C}$ by day and $18^{\circ} \mathrm{C}$ by night. $F$. oxysporum isolates were cultured at room temperature $\left(23 \pm 1^{\circ} \mathrm{C}\right)$ under ambient light on half-strength potato dextrose agar (PDA) (Difco Laboratories, Sparks, MD, U.S.A.) amended with $100 \mathrm{ppm}$ of chloramphenicol. A microconidial suspension of each isolate was prepared by inoculating $250 \mathrm{ml}$ of Kerr's broth (Kerr 1963) with three $1-\mathrm{mm}^{3}$ colonized agar plugs taken from the leading edge of a colony. The inoculated broth was incubated at room temperature under ambient light on a gyratory shaker at $125 \mathrm{rpm}$ for 7 days. Each microconidial suspension was then filtered through cheesecloth, and the spore concentration was quantified with a hemocytometer. For each of the six trials, spinach plants were inoculated either by drenching the root plugs of 12-day-old spinach plants or by planting seed into propagation mix inoculated with the spore suspension. For the latter, the microconidial suspension was sprayed onto the propagation mix in a Gustafson batch seed treater (Gustafson LLC., Shakopee, MN, U.S.A.), and was tumbled for $5 \mathrm{~min}$ to mix the propagation medium and inoculum thoroughly. The inoculated propagation medium was then distributed into the 6-cell packs, and the seeds were sown. In all six trials, the concentration of microconidia was $1.25 \times$ 
$10^{4}$ spores per milliliter of propagation mix. Twelve days after spinach seeds had been sown, the temperature in the greenhouse or growth chamber was increased to $28^{\circ} \mathrm{C}$ by day and $24^{\circ} \mathrm{C}$ by night, to promote transpirational demand and, thereby, development of Fusarium wilt symptoms (Naiki and Morita 1983). The spinach plants were rated for severity of wilt weekly, using an ordinal scale of 0 (no wilt) to 5 (dead plant). Ratings were converted to a Fusarium wilt severity index (Gatch and du Toit 2015). The area under the disease progress curve (AUDPC) was calculated based on this index, using the trapezoidal method (Sparks et al. 2008).

The repeat pathogenicity trials for the isolates selected for whole-genome sequencing were performed on spinach inbred lines $\mathrm{A}$ and $\mathrm{C}$ by inoculating the propagation mix, as described previously, to achieve $3.75 \times 10^{4}$ microconidia per millliliter of propagation mix. The trial was conducted in a growth chamber (Percival, Perry, IA, U.S.A.) for 39 days (trial 1) and was then repeated in a greenhouse (trial 2) for 35 days, as the daylength had shortened enough in the autumn to prevent bolting of the spinach plants. In addition to scoring wilt severity, the aboveground dry biomass of the spinach plants in each replicated plot (6-pack) for each treatment combination was determined after drying the plants at $65^{\circ} \mathrm{C}$ for $72 \mathrm{~h}$.

\section{Data analyses for the pathogenicity trials.}

Data for the pathogenicity trials were summarized and visualized with the R-package suite Tidyverse (Wickham et al. 2019). Statistical analyses were performed in SAS version 9.4 (SAS Institute, Cary, NC, U.S.A.) with PROC MIXED, and PROC CORR was used to calculate Pearson's correlation coefficients for weekly disease ratings, the AUDPC, and dry biomass per plant. Log, square root, or arcsine square root transformations were used to transform response data when one or both parametric assumptions of normally distributed residuals or homogeneous variances were not met. If the transformed response data did not meet parametric assumptions for ANOVA, the response variable was rank-transformed and statistical analyses performed on the ranked data. Mean separation tests were calculated with Fisher's protected least significant difference at $P<0.05$, and means were grouped with pdmix 800 (Saxton 1998).

\section{DNA extraction and molecular characterization of Fusarium isolates.}

The Fusarium isolates listed in Supplementary Table S1 were each grown on half-strength PDA amended with $100 \mathrm{ppm}$ of chloramphenicol, from which two $3-\mathrm{mm}^{3}$ colonized agar plugs were taken from the leading edge of the colony and placed in $75 \mathrm{ml}$ of potato dextrose broth in a $125 \mathrm{ml}$ Erlenmeyer flask. Each inoculated flask was placed on an orbital shakingplatform operated at $125 \mathrm{rpm}$ at room temperature for 7 days under ambient light. The resulting mycelium was vacuumfiltered and frozen at $-80^{\circ} \mathrm{C}$ for $24 \mathrm{~h}$. DNA was extracted from the mycelium with the FastDNA kit (MP Biomedicals, Santa Ana, CA, U.S.A.). The concentration of DNA was assessed on a Qubit fluorometer (Invitrogen, Carlsbad, CA, U.S.A.).

The Fusarium isolates were each identified to species, based on morphology and the DNA sequence of a partial region of the TEF 1- $\alpha$ gene. In brief, TEF $1-\alpha$ was amplified with primers 526F (GTC GTY GTY ATY GGH CAY GT) (S. Rehner personal communication) and 1567R (ACH GTR CCR ATA CCA CCR ATC TT) (Rehner and Buckley 2005) and the following PCR protocol: 1 cycle of $2 \mathrm{~min}$ at $94^{\circ} \mathrm{C} ; 9$ cycles of $30 \mathrm{~s}$ at $94^{\circ} \mathrm{C}, 30 \mathrm{~s}$ at $66^{\circ} \mathrm{C}$, and $1{ }^{\circ} \mathrm{C}$ lower for each subsequent cycle, and $1.5 \mathrm{~min}$ at $72^{\circ} \mathrm{C} ; 28$ cycles of $30 \mathrm{~s}$ at $94^{\circ} \mathrm{C}, 30 \mathrm{~s}$ at $56^{\circ} \mathrm{C}$, and $1.5 \mathrm{~min}$ at $72^{\circ} \mathrm{C}$; followed by 1 cycle for $10 \mathrm{~min}$ at $72^{\circ} \mathrm{C}$. The PCR products were visualized on a $1.5 \%$ agarose gel $(1 \times$ Tris-
borate-EDTA buffer) using GelRed (Biotium, Fremont, CA U.S.A.). The DNA fragments were purified with ExoSAP-IT (Applied Biosystems, Foster City, CA, U.S.A.) and were quantified with a Qubit fluorometer. Purified DNA fragments were sequenced bidirectionally at Elim Biopharmaceuticals (Hayward, CA, U.S.A.). The consensus sequences for all TEF 1- $\alpha$ DNA fragments were deposited in GenBank (Supplementary Table S1). A maximum likelihood tree was estimated for the TEF1- $\alpha$ sequences by manual alignment of the DNA sequences. The best-fit model for each alignment was selected by Bayesian information criterion (BIC) with ModelTest-NG (Darriba et al. 2020), and a maximum-likelihood tree was inferred using the best-fit evolutionary model with RAxMLNG (Kozlov et al. 2019) and 1,000 bootstrap replicates to estimate node support.

\section{Genome sequencing.}

DNA of each of $F$. oxysporum f. sp. spinaciae isolates Fus001, Fus057, Fus059, Fus167, Fus173, Fus254, and Fus322 and NPS isolates Fus017, Fus187, Fus191, Fus250, and Fus259 was extracted from approximately $100 \mathrm{mg}$ of frozen mycelium, using the Purelink plant total DNA purification kit (Invitrogen), according to manufacturer protocol. Genomic DNA concentration and integrity were determined with a Qubit fluorometer and gel electrophoresis, respectively. Library preparation and sequencing were completed by Molecular Research DNA Lab (Shallowater, TX, U.S.A.). Eleven isolates (Fus001, Fus017, Fus057, Fus059, Fus167, Fus173, Fus187, Fus191, Fus250, Fus259, and Fus322) were sequenced with the Illumina HiSeq platform $(2 \times 250 \mathrm{bp}$, approximately 10 million reads per paired end). The DNA samples were prepared with the KAPA HyperPlus kits (Roche, Basel, Switzerland), following manufacturer protocol. In addition, genomic DNA isolated from F. oxysporum f. sp. spinaciae isolate Fus254 was sequenced using the PacBio Sequel platform (Pacific Biosciences). Fus254 had been characterized extensively in prior pathogenicity trials. Isolate Fus 254 was sequenced with a long-read platform to generate a draft genome assembly of one $F$. oxysporum f. sp. spinaciae isolate with greater contiguity than the Illumina-generated assemblies. The library for Fus254 was prepared using SMRTbell template prep kit (Pacific Biosciences), following manufacturer protocol. The DNA of Fus254 was sheared to a size of approximately $7.2 \mathrm{Kbp}$, using the Covaris G-tube (Covaris Inc., Woburn, MA, U.S.A.), and the library pool was sequenced on two SMRT Cells, using a 10$\mathrm{h}$ movie time, on the PacBio Sequel (Pacific Biosciences).

In addition to the 12 isolates tested three times for pathogenicity on spinach, as described above, three $F$. oxysporum $\mathrm{f}$. sp. spinaciae isolates from the United States Department of Agriculture Agricultural Research Service (USDA ARS) culture collection at the Northern Regional Research Laboratory (NRRL) were used for whole-genome sequencing completed at the University of Amsterdam in Amsterdam, Netherlands: Fus165 = NRRL26874, Fus166 = NRRL26875, and Fus167 = NRRL26876. DNA was extracted from freeze-dried mycelium harvested from 5-day-old $\mathrm{NO}_{3}$-broth $(0.17 \%$ yeast nitrogen base, $3 \%$ sucrose, $100 \mathrm{mM} \mathrm{KNO}_{3}$ ) cultures. The mycelium from each isolate was ground in a mortar with liquid nitrogen. Approximately $25 \mathrm{mg}$ of ground mycelium was added to a prechilled tube containing three metal beads, and $800 \mu \mathrm{l}$ of sodium dodecyl sulfate (SDS) extraction buffer (100 mM Tris, pH 8.0, $50 \mathrm{mM}$ EDTA, $1 \mathrm{M} \mathrm{NaCl}, 3 \%$ SDS) was added. The samples were shaken for $2 \mathrm{~min}$ at max speed in a Tissue Lyser (Qiagen, Hilden, Germany) and were incubated at $65^{\circ} \mathrm{C}$ for $30 \mathrm{~min}$. Then, $800 \mu \mathrm{l}$ of phenol/chloroform/isoamylalcohol (25: $24: 1$, buffer saturated phenol) was added to the lysed tissue, the sample was mixed by inversion, and was centrifuged at 
maximum speed at $4{ }^{\circ} \mathrm{C}$ for $15 \mathrm{~min}$. DNA was precipitated from the aqueous phase with a 0.1 volume of $5 \mathrm{M} \mathrm{NaCl}$ and two volumes of $96 \%$ ethanol. The resulting DNA was purified with the Purelink plant total DNA purification kit (Invitrogen). Libraries were prepared for the three isolates with a the TruSeq Nano DNA low throughput library prep kit (Illumina, San Diego, CA, U.S.A.), following manufacturer protocol, and were sequenced with the Illumina HiSeq X Ten platform $(2 \times 150 \mathrm{bp})$ by the Hartwig Medical Foundation (Amsterdam).

\section{Raw read data and genome assembly.}

The sequence reads of the 14 isolates of $F$. oxysporum were deposited in the sequence read archive (SRA) under the BioProject numbers PRJNA540981 and PRJNA595149. The corresponding assemblies were deposited in the NCBI GenBank repository (Table 2). Illumina reads were quality-trimmed using Trimmomatic version 0.39 (Bolger et al. 2014) with a quality threshold of 20, and the Illumina adapters were removed. PhiX phage contamination was found in the Illumina reads generated for 11 of the $F$. oxysporum isolates (in 0.01 to $0.07 \%$ of the total reads for those isolates). Reads of PhiX origin were then removed by mapping the trimmed Illumina reads to the genome of Coliphage phi-X174 (NC_001422.1) with Bowtie 2 (Langmead and Salzberg 2012). Unmapped, PhiX-free Illumina reads of the 11 isolates were then assembled with SPAdes v3.13.0 (Bankevich et al. 2012), with default kmer sizes of 21, 33, 55, 77, 99, and 127. The Illumina reads for the genomes of Fus165, Fus166, and Fus167vB were assembled with CLC-Workbench version 8.0 (Qiagen), with default parameters. De novo assembly of the PacBio reads of isolate Fus 254 was accomplished using the SMRT Analysis Hierarchical Genome Assembly Process version 3.0. The expected genome size was estimated to be $50 \mathrm{Mbp}$, based on the genomes of other $F$. oxysporum $\mathrm{ff}$. spp. sequenced (Ma et al. 2010; van Dam et al. 2016). General assembly statistics were calculated with QUAST (Gurevich et al. 2013). BUSCOs were identified in the newly generated assemblies as an estimate of genome completeness with the Sordariomycete (odb9) database (Simão et al. 2015) (Table 2).

\section{Phylogenomic analyses.}

Phylogenetic summary trees were inferred by comparing BUSCOs identified from whole-genome sequences of the nine F. oxysporum f. sp. spinaciae isolates, five NPS isolates, 13 publicly available $F$. oxysporum genome assemblies, and genome sequences of two other Fusarium spp. downloaded from GenBank (Supplementary Table S2). In total, 3,127 singlecopy, nonfragmented BUSCOs common among all 30 genome assemblies were used for phylogenetic analyses. Each BUSCO was aligned among the taxa using Clustal Omega (Sievers et al. 2011), the best-fit model for each alignment was selected by BIC with ModelTest-NG (Darriba et al. 2020), and a maximumlikelihood tree was inferred for each of the BUSCOs, using the best-fit evolutionary model with RAxML-NG (Kozlov et al. 2019). The parameters used for RAxML-NG included an expanded tree search (100 parsimony and 100 maximum likelihood start trees) without bootstrapping. The 3,127 maximumlikelihood trees were used in ASTRAL-III to estimate the best species tree given the gene trees (Zhang et al. 2018). The final tree produced by ASTRAL-III was rooted to $F$. solani. In addition to the ASTRAL-inferred species tree, the 3,127 aligned BUSCOs were concatenated, resulting in 6,222,831 alignment sites from which a tree was inferred, as described previously, with the exception that a single model of evolution (GTR + I + $\mathrm{G})$ was used for the entire concatenated data set, and 1,000 bootstrap replicates were performed to estimate clade support (Supplementary Fig. S3). The resulting newick trees were visualized with FigTree version 1.4.4 or the web-based tree-editor phylo.io.
Unaligned and aligned FASTA files of BUSCOs and phylogenetic trees (in newick format) will be made available on request.

\section{Effector gene prediction.}

A prediction pipeline was used to identify putative effector genes associated with mimps among the $10 F$. oxysporum $\mathrm{f}$. sp. spinaciae and five NPS genome assemblies generated in this study (van Dam et al. 2016). In brief, open reading frames (ORFs) were predicted within 2,000 bp downstream of each mimp-identified ORF that translated into a protein with between 25 and 600 amino acids and had a predicted signal peptide (assessed with SignalP 4.0 [Petersen et al. 2011]). These were designated as putative effectors. In addition, homologs of the 14 known SIX genes of F. oxysporum f. sp. lycopersici were searched for in the genome assemblies of the $F$. oxysporum f. sp. spinaciae and NPS isolates, using the command line tool BLASTN with the flag '-outfmt 6'. When fragmented SIX genes were found in the assemblies, trimmed Illumina reads were mapped to the 14 SIX genes with Bowtie 2 (Langmead and Salzberg 2012) and the consensus sequence was extracted with bcftools ( $\mathrm{Li}$ et al. 2009). Each predicted effector gene was investigated for putative function by using BLASTX and InterProScan with the program Blast2GO version 5.2.5 (Conesa et al. 2005). To identify $F$. oxysporum f. sp. spinaciae-specific effector genes from the pipeline described by van Dam et al. (2016), the predicted effector genes were searched with the BLASTN command line tool with default parameters against 222 other $F$. oxysporum genome assemblies present in GenBank as of January 1, 2020.

\section{Genomic comparison of $\boldsymbol{F}$. oxysporum f. sp. spinaciae and} F. oxysporum f. sp. lycopersici.

The organization of the genomes of $F$. oxysporum f. sp. lycopersici isolate 4287 (GCA_000149955.2) and F. oxysporum $\mathrm{f}$. sp. spinaciae isolate Fus254 were compared using Circos version 0.69-8 (Krzywinski et al. 2009). Common, single-copy Sordariomycete orthologs inferred with BUSCO $(n=3,533)$ were linked to demonstrate synteny, the 14 SIX genes and putative effector genes were located in both genome assemblies using the command line version of BLASTN with default parameters, and mimp sequences were identified using SeqKit (Shen et al. 2016) with the following command 'seqkit locate-bed -d -p NNCAGT[GA][GA] G[GAT][TGC]GCAA[TAG]AA’ (Fig. 5).

\section{ACKNOWLEDGMENTS}

Cultures of Fusarium were contributed by J. Correll (University of Arkansas), F. Dugan (USDA ARS), T. Gordon (University of CaliforniaDavis), L. Hanson (USDA ARS), S. Hartney (Sakata Seed America), and H. Schwartz (Colorado State University). The authors thank E. M. Andrews, M. Derie, H. Fukada, B. Holmes, S. Gyawali, P. Morgan, and R. Solemslie for technical assistance with pathogenicity testing and DNA extractions from Fusarium isolates. The authors thank M. de Sain for isolating DNA from the genomes of three $F$. oxysporum f. sp. spinaciae isolates (Fus165, Fus166, and Fus167), assembly of these genomes, and for review of this manuscript. The authors thank E. Roalson and C. Gleason (Washington State University) for reviewing this manuscript.

\section{AUTHOR-RECOMMENDED INTERNET RESOURCES}

FigTree version 1.4.4: https://github.com/rambaut/figtree phylo.io: https://phylo.io

\section{LITERATURE CITED}

Alabouvette, C., Olivain, C., Migheli, Q., and Steinberg, C. 2009. Microbiological control of soil-borne phytopathogenic fungi with special emphasis on wilt-inducing Fusarium oxysporum. New Phytol. 184:529-544.

Armitage, A. D., Taylor, A., Sobczyk, M. K., Baxter, L., Greenfield, B. P. J., Bates, H. J., Wilson, F., Jackson, A. C., Ott, S., Harrison, R. J., and 
Clarkson, J. P. 2018. Characterisation of pathogen-specific regions and novel effector candidates in Fusarium oxysporum f. sp. cepae. Sci. Rep. $8: 13530$.

Armstrong, G. M., and Armstrong, J. K. 1976. Common hosts for Fusarium oxysporum formae speciales spinaciae and betae. Phytopathology 66 : 542-545.

Baayen, R. P., O’Donnell, K., Bonants, P. J. M., Cigelnik, E., Kroon, L. P. N. M., Roebroeck, E. J. A., and Waalwijk, C. 2000. Gene genealogies and AFLP analyses in the Fusarium oxysporum complex identify monophyletic and nonmonophyletic formae speciales causing wilt and rot disease. Phytopathology 90:891-900.

Bankevich, A., Nurk, S., Antipov, D., Gurevich, A. A., Dvorkin, M., Kulikov, A. S., Lesin, V. M., Nikolenko, S. I., Pham, S., Prjibelski, A. D., Pyshkin, A. V., Sirotkin, A. V., Vyahhi, N., Tesler, G., Alekseyev, M. A., and Pevzner, P. A. 2012. SPAdes: A new genome assembly algorithm and its applications to single-cell sequencing. J. Comput. Biol. 19:455477.

Batson, A., Gyawali, S., and du Toit, L. J. 2020. Evaluation of spinach and Beta vulgaris cultivars for differential susceptibility to two pathogenicity groups of Fusarium oxysporum f. sp. spinaciae. (Abstr. Pages S2.117-S2.118). Phytopathology 110:S2.1. doi.org/10.1094/PHYTO-110-12-S2.1

Bolger, A. M., Lohse, M., and Usadel, B. 2014. Trimmomatic: A flexible trimmer for Illumina sequence data. Bioinformatics 30:2114-2120.

Cafri, D., Katan, J., and Katan, T. 2005. Cross-pathogenicity between formae speciales of Fusarium oxysporum pathogens of cucumber and melon. J. Phytopathol. 153:615-622.

Carvalhais, L. C., Henderson, J., Rincon-Florez, V. A., O'Dwyer, C., Czislowski, E., Aitken, E. A. B., and Drenth, A. 2019. Molecular diagnostics of banana Fusarium wilt targeting Secreted-in-Xylem genes. Front. Plant Sci. 10:547.

Catanzariti, A. M., Lim, G. T. T., and Jones, D. A. 2015. The tomato I-3 gene: A novel gene for resistance to Fusarium wilt disease. New Phytol. 207:106-118.

Coleman, J. J., Rounsley, S. D., Rodriguez-Carres, M., Kuo, A., Wasmann, C. C., Grimwood, J., Schmutz, J., Taga, M., White, G. J., Zhou, S., Schwartz, D. C., Freitag, M., Ma, L. J., Danchin, E. G. J., Henrissat, B., Coutinho, P. M., Nelson, D. R., Straney, D., Napoli, C. A., Barker, B. M., Gribskov, M., Rep, M., Kroken, S., Molnár, I., Rensing, C., Kennell, J. C., Zamora, J., Farman, M. L., Selker, E. U., Salamov, A., Shapiro, H., Pangilinan, J., Lindquist, E., Lamers, C., Grigoriev, I. V., Geiser, D. M., Covert, S. F., Temporini, E., and Vanetten, H. D. 2009. The genome of Nectria haematococca: Contribution of supernumerary chromosomes to gene expansion. PLoS Genet. 5:e1000618.

Conesa, A., Götz, S., García-Gómez, J. M., Terol, J., Talón, M., and Robles, M. 2005. Blast2GO: A universal tool for annotation, visualization and analysis in functional genomics research. Bioinformatics 21:36743676.

Covey, P. A., Kuwitzky, B., Hanson, M., and Webb, K. M. 2014. Multilocus analysis using putative fungal effectors to describe a population of Fusarium oxysporum from sugar beet. Phytopathology 104:886-896.

Czislowski, E., Fraser-Smith, S., Zander, M., O’Neill, W. T., Meldrum, R. A., Tran-Nguyen, L. T. T., Batley, J., and Aitken, E. A. B. 2018. Investigation of the diversity of effector genes in the banana pathogen, Fusarium oxysporum f. sp. cubense, reveals evidence of horizontal gene transfer. Mol. Plant Pathol. 19:1155-1171.

Darriba, D., Posada, D., Kozlov, A. M., Stamatakis, A., Morel, B., and Flouri, T. 2020. ModelTest-NG: A new and scalable tool for the selection of DNA and protein evolutionary models. Mol. Biol. Evol. 37:291294.

de Jonge, R., van Esse, H. P., Kombrink, A., Shinya, T., Desaki, Y., Bours, R., van der Krol, S., Shibuya, N., Joosten, M. H. A. J., and Thomma, B. P. H. J. 2010. Conserved fungal LysM effector Ecp6 prevents chitintriggered immunity in plants. Science 329:953-955.

Deltour, P., França, S. C., Heyman, L., Pereira, O. L., and Höfte, M. 2018. Comparative analysis of pathogenic and nonpathogenic Fusarium oxysporum populations associated with banana on a farm in Minas Gerais, Brazil. Plant Pathol. 67:707-718.

du Toit, L. J., Derie, M. L., Holmes, B. J., and Youngquist, C. P. 2014. Effect of Proline and a biosolids compost on Fusarium and Verticillium wilts in a spinach seed crop, 2013. Plant Disease Management Reports 8:V280.

du Toit, L. J., Miller, T. W., Derie, M. L., Maupin, B., Peterson, R., and Libbey, C. 2004. Evaluation of mustard cover/biofumigant crops for management of Fusarium wilt in spinach seed crops, 2002-2003. Biological \& Cultural Tests 19:V004.

du Toit, L. J., Miller, T. W., Libbey, C. R., Derie, M. L., and Peterson, R. K. 2006. Evaluation of mustard cover/biofumigant crops for management of Fusarium wilt in spinach seed crops, 2004-2005. Biological \& Cultural Tests 21:V001. du Toit, L. J., and Ocamb, C. M. 2019. Spinach (Spinacia oleracea)Fusarium wilt. 2019 Pacific Northwest Plant Disease Management Handbook. J. W. Pscheidt and C. M. Ocamb, eds. Oregon State University, Corvallis, OR, U.S.A.

Edel-Hermann, V., and Lecomte, C. 2019. Current status of Fusarium oxysporum formae speciales and races. Phytopathology 109:512-530.

Fiely, M. B., Correll, J. C., and Morelock, T. E. 1995. Vegetative compatibility, pathogenicity, and virulence diversity of Fusarium oxysporum recovered from spinach. Plant Dis. 79:990-993.

Foss, C. R., and Jones, L. J. 2005. Crop profile for spinach seed in Washington. U.S. Department of Agriculture National Pest Management Regional IPM Center, Davis, CA, U.S.A. https://ipmdata.ipmcenters. org/documents/cropprofiles/WAspinachseed.pdf

Gatch, E. W. 2013. Management of Fusarium wilt in spinach seed crops in the maritime Pacific Northwest USA. Ph.D. dissertation. Washington State University, Pullman, WA, U.S.A.

Gatch, E. W., and du Toit, L. J. 2015. A soil bioassay for predicting the risk of spinach Fusarium wilt. Plant Dis. 99:512-526.

Gatch, E. W., and du Toit, L. J. 2017. Limestone-mediated suppression of Fusarium wilt in spinach seed crops. Plant Dis. 101:81-94.

Gawehns, F., Houterman, P. M., Ichou, F. A., Michielse, C. B., Hijdra, M., Cornelissen, B. J. C., Rep, M., and Takken, F. L. W. 2014. The Fusarium oxysporum effector Six6 contributes to virulence and suppresses I-2mediated cell death. Mol. Plant-Microbe Interact. 27:336-348.

Gerdemann, J. W., and Finley, A. M. 1951. The pathogenicity of races 1 and 2 of Fusarium oxysporum f. sp. lycopersici. Phytopathology 41:238244.

Gordon, T. R., and Martyn, R. D. 1997. The evolutionary biology of Fusarium oxysporum. Annu. Rev. Phytopathol. 35:111-128.

Gurevich, A., Saveliev, V., Vyahhi, N., and Tesler, G. 2013. QUAST: Quality assessment tool for genome assemblies. Bioinformatics 29: 1072-1075

Gyawali, S., du Toit, L. J., Shi, A., and Correll, J. C. 2019. Genome wide association studies of Fusarium wilt resistance in spinach (Spinacia oleracea L.). Abstr. Phytopathology 109(S2):83-84.

Houterman, P. M., Cornelissen, B. J., and Rep, M. 2008. Suppression of plant resistance gene-based immunity by a fungal effector. PLoS Pathog. 4:e1000061.

Houterman, P. M., Ma, L., van Ooijen, G., de Vroomen, M. J., Cornelissen, B. J. C., Takken, F. L. W., and Rep, M. 2009. The effector protein Avr2 of the xylem-colonizing fungus Fusarium oxysporum activates the tomato resistance protein I-2 intracellularly. Plant J. 58:970-978.

Jelinski, N. A., Broz, K., Jonkers, W., Ma, L. J., and Kistler, H. C. 2017. Effector gene suites in some soil isolates of Fusarium oxysporum are not sufficient predictors of vascular wilt in tomato. Phytopathology 107:842-851.

Kerr, A. 1963. The root rot-Fusarium wilt complex of peas. Aust. J. Biol. Sci. 16:55-69.

Kistler, H. C. 1997. Genetic diversity in the plant-pathogenic fungus Fusarium oxysporum. Phytopathology 87:474-479.

Kozlov, A. M., Darriba, D., Flouri, T., Morel, B., and Stamatakis, A. 2019. RAxML-NG: A fast, scalable and user-friendly tool for maximum likelihood phylogenetic inference. Bioinformatics 35:4453-4455.

Krzywinski, M., Schein, J., Birol, I., Connors, J., Gascoyne, R., Horsman, D., Jones, S. J., and Marra, M. A. 2009. Circos: An information aesthetic for comparative genomics. Genome Res. 19:1639-1645.

Laguna, R. J. 2000. Screening for resistance to Fusarium wilt of spinach. MS thesis. University of Arkansas, Fayetteville, AR, U.S.A.

Langmead, B., and Salzberg, S. L. 2012. Fast gapped-read alignment with Bowtie 2. Nat. Methods 9:357-359.

Laurence, M. H., Summerell, B. A., Burgess, L. W., and Liew, E. C. Y. 2014. Genealogical concordance phylogenetic species recognition in the Fusarium oxysporum species complex. Fungal Biol. 118:374-384.

Laurence, M. H., Summerell, B. A., and Liew, E. C. Y. 2015. Fusarium oxysporum f. sp. canariensis: Evidence for horizontal gene transfer of putative pathogenicity genes. Plant Pathol. 64:1068-1075.

Leslie, J. F., and Summerell, B. A. 2006. The Fusarium Laboratory Manual. Blackwell Publishing, Ames, IA, U.S.A.

Li, H., Handsaker, B., Wysoker, A., Fennell, T., Ruan, J., Homer, N., Marth, G., Abecasis, G., Durbin, R., and 1000 Genome Project Data Processing Subgroup. 2009. The sequence alignment/map (SAM) format and SAMtools. Bioinformatics 25:2078-2079.

Li, J., Fokkens, L., van Dam, P., and Rep, M. 2020. Related mobile pathogenicity chromosomes in Fusarium oxysporum determine host range on cucurbits. Mol. Plant Pathol. 21:761-776.

Lievens, B., Houterman, P. M., and Rep, M. 2009. Effector gene screening allows unambiguous identification of Fusarium oxysporum f. sp. lycopersici races and discrimination from other formae speciales. FEMS Microbiol. Lett. 300:201-215. 
Lombard, L., Sandoval-Denis, M., Lamprecht, S. C., and Crous, P. W. 2019. Epitypification of Fusarium oxysporum - clearing the taxonomic chaos. Persoonia 43:1-47.

Ma, L., Houterman, P. M., Gawehns, F., Cao, L., Sillo, F., Richter, H., Clavijo-Ortiz, M. J., Schmidt, S. M., Boeren, S., Vervoort, J., Cornelissen, B. J. C., Rep, M., and Takken, F. L. W. 2015. The AVR2SIX5 gene pair is required to activate I-2-mediated immunity in tomato. New Phytol. 208:507-518.

Ma, L. J., van der Does, H. C., Borkovich, K. A., Coleman, J. J., Daboussi, M. J., Di Pietro, A., Dufresne, M., Freitag, M., Grabherr, M., Henrissat, B., Houterman, P. M., Kang, S., Shim, W. B., Woloshuk, C., Xie, X., Xu, J. R., Antoniw, J., Baker, S. E., Bluhm, B. H., Breakspear, A., Brown, D. W., Butchko, R. A., Chapman, S., Coulson, R., Coutinho, P. M., Danchin, E. G., Diener, A., Gale, L. R., Gardiner, D. M., Goff, S., Hammond-Kosack, K. E., Hilburn, K., Hua-Van, A., Jonkers, W., Kazan, K., Kodira, C. D., Koehrsen, M., Kumar, L., Lee, Y. H., Li, L., Manners, J. M., Miranda-Saavedra, D., Mukherjee, M., Park, G., Park, J., Park, S. Y., Proctor, R. H., Regev, A., Ruiz-Roldan, M. C., Sain, D., Sakthikumar, S., Sykes, S., Schwartz, D. C., Turgeon, B. G., Wapinski, I., Yoder, O., Young, S., Zeng, Q., Zhou, S., Galagan, J., Cuomo, C. A., Kistler, H. C., and Rep, M. 2010. Comparative genomics reveals mobile pathogenicity chromosomes in Fusarium. Nature 464:367-373.

MacDonald, J. D., and Leach, L. D. 1976. Evidence for an expanded host range of Fusarium oxysporum f. sp. betae. Phytopathology 66:822-827.

Malvick, D. K., Percich, J. A., Pflegler, F. L., Givens, J., and Williams, J. L. 1994. Evaluation of methods for estimating inoculum potential of Aphanomyces euteiches in soil. Plant Dis. 78:361-365.

Maryani, N., Lombard, L., Poerba, Y. S., Subandiyah, S., Crous, P. W., and Kema, G. H. J. 2019. Phylogeny and genetic diversity of the banana Fusarium wilt pathogen Fusarium oxysporum f. sp. cubense in the Indonesian centre of origin. Stud. Mycol. 92:155-194.

McGrath, D. J., Gillespie, D., and Vawdrey, L. 1987. Inheritance of resistance to Fusarium oxysporum f. sp. lycopersici races 2 and 3 in Lycopersicon pennelli. Aust. J. Agric. Res. 38:729-733.

Meldrum, R. A., Fraser-Smith, S., Tran-Nguyen, L. T. T., Daly, A. M., and Aitken, E. A. B. 2012. Presence of putative pathogenicity genes in isolates of Fusarium oxysporum f. sp. cubense from Australia. Austral. Plant Pathol. 41:551-557.

Metzger, J. D., and Zeevaart, J. A. D. 1985. Spinacia oleracea. Pages 384392 in: CRC Handbook of Flowering Plants. A. H. Halevy, ed. Vol. IV. CRC Press, Boca Raton, FL, U.S.A.

Naiki, T., and Kano, M. 1977. On Fusarium wilt of spinach and its causal fungus. Ann. Phytopathol. Soc. Jpn. 43:297-300.

Naiki, T., and Morita, Y. 1983. The population of spinach wilt fungus, Fusarium oxysporum f. sp. spinaciae, and the wilt incidence in soil. Ann. Phytopathol. Soc. Jpn. 49:539-544.

Nucci, M., and Anaissie, E. 2002. Cutaneous infection by Fusarium species in healthy and immunocompromised hosts: Implications for diagnosis and management. Clin. Infect. Dis. 35:909-920.

O'Brien, M. J., and Winters, H. F. 1977. Evaluation of spinach accessions and cultivars for resistance to Fusarium wilt. I. Greenhouse-bench method. J. Am. Soc. Hortic. Sci. 102:424-426.

O’Donnell, K., Gueidan, C., Sink, S., Johnston, P. R., Crous, P. W., Glenn, A., Riley, R., Zitomer, N. C., Colyer, P., Waalwijk, C., Lee, T., Moretti, A., Kang, S., Kim, H. S., Geiser, D. M., Juba, J. H., Baayen, R. P., Cromey, M. G., Bithell, S., Sutton, D. A., Skovgaard, K., Ploetz, R., Corby Kistler, H., Elliott, M., Davis, M., and Sarver, B. A. J. 2009. A two-locus DNA sequence database for typing plant and human pathogens within the Fusarium oxysporum species complex. Fungal Genet. Biol. 46:936-948.

Okubara, P. A., Harrison, L. A., Gatch, E. W., Vandemark, G., Schroeder, K. L., and du Toit, L. J. 2013. Development and evaluation of a TaqMan real-time PCR assay for Fusarium oxysporum f. sp. spinaciae. Plant Dis. 97:927-937.

Organic Seed Alliance. 2007. Principles and practices of organic spinach seed production in the Pacific Northwest. Organic Seed Alliance, Port Townsend, WA, U.S.A. https://seedalliance.org/publications/principlespractices-organic-spinach-seed-production-pacific-northwest/

Oyarzun, P. J., Dijst, G., and Maas, P. W. Th. 1994. Determination and analysis of soil receptivity to Fusarium solani $\mathrm{f}$. sp. pisi causing dry root rot of peas. Phytopathology 84:834-842.

Petersen, T. N., Brunak, S., von Heijne, G., and Nielsen, H. 2011. SignalP 4.0: Discriminating signal peptides from transmembrane regions. Nat. Methods 8:785-786.

Ponukumati, S. V., Elliott, M. L., and Des Jardin, E. A. 2019. Comparison of Secreted in Xylem (SIX) genes in two Fusarium wilt pathogens of ornamental palms. Plant Pathol. 68:1663-1681.
Rehner, S. A., and Buckley, E. 2005. A Beauveria phylogeny inferred from nuclear ITS and EF1- $\alpha$ sequences: Evidence for cryptic diversification and links to Cordyceps teleomorphs. Mycologia 97:84-98.

Rep, M. 2005. Small proteins of plant-pathogenic fungi secreted during host colonization. FEMS Microbiol. Lett. 253:19-27.

Rep, M., van der Does, H. C., Meijer, M., van Wijk, R., Houterman, P. M., Dekker, H. L., de Koster, C. G., and Cornelissen, B. J. C. 2004. A small, cysteine-rich protein secreted by Fusarium oxysporum during colonization of xylem vessels is required for I-3-mediated resistance in tomato. Mol. Microbiol. 53:1373-1383.

Rocha, L. O., Laurence, M. H., Ludowici, V. A., Puno, V. I., Lim, C. C., Tesoriero, L. A., Summerell, B. A., and Liew, E. C. Y. 2016. Putative effector genes detected in Fusarium oxysporum from natural ecosystems of Australia. Plant Pathol. 65:914-929.

Saxton, A. M. 1998. A macro for converting mean separation output to letter groupings in Proc Mixed. Pp. 1243-1246. In: Proceedings of the 23rd SAS Users Group Intl., SAS Institute, Cary, NC, U.S.A.

Schmidt, S. M., Houterman, P. M., Schreiver, I., Ma, L., Amyotte, S., Chellappan, B., Boeren, S., Takken, F. L. W., and Rep, M. 2013. MITEs in the promoters of effector genes allow prediction of novel virulence genes in Fusarium oxysporum. BMC Genomics 14:119.

Schmidt, S. M., Lukasiewicz, J., Farrer, R., van Dam, P., Bertoldo, C., and Rep, M. 2016. Comparative genomics of Fusarium oxysporum f. sp. melonis reveals the secreted protein recognized by the Fom-2 resistance gene in melon. New Phytol. 209:307-318.

Shahi, S., Beerens, B., Bosch, M., Linmans, J., and Rep, M. 2016. Nuclear dynamics and genetic rearrangement in heterokaryotic colonies of Fusarium oxysporum. Fungal Genet. Biol. 91:20-31.

Shen, W., Le, S., Li, Y., and Hu, F. 2016. SeqKit: A cross-platform and ultrafast toolkit for FASTA/Q file manipulation. PLoS One 11:e0163962.

Sievers, F., Wilm, A., Dineen, D., Gibson, T. J., Karplus, K., Li, W., Lopez, R., McWilliam, H., Remmert, M., Söding, J., Thompson, J. D., and Higgins, D. G. 2011. Fast, scalable generation of high-quality protein multiple sequence alignments using Clustal Omega. Mol. Syst. Biol. 7:539.

Simão, F. A., Waterhouse, R. M., Ioannidis, P., Kriventseva, E. V., and Zdobnov, E. M. 2015. BUSCO: Assessing genome assembly and annotation completeness with single-copy orthologs. Bioinformatics 31 : 3210-3212.

Simbaqueba, J., Catanzariti, A. M., González, C., and Jones, D. A. 2018. Evidence for horizontal gene transfer and separation of effector recognition from effector function revealed by analysis of effector genes shared between cape gooseberry- and tomato-infecting formae speciales of Fusarium oxysporum. Mol. Plant Pathol. 19:2302-2318.

Simons, G., Groenendijk, J., Wijbrandi, J., Reijans, M., Groenen, J., Diergaarde, P., Van der Lee, T., Bleeker, M., Onstenk, J., de Both, M., Haring, M., Mes, J., Cornelissen, B., Zabeau, M., and Vos, P. 1998. Dissection of the Fusarium 12 gene cluster in tomato reveals six homologs and one active gene copy. Plant Cell 10:1055-1068.

Sparks, A. H., Esker, P. D., Bates, M., Dall'Acqua, W., Guo, Z., Segovia, V., Silwal, S. D., Tolos, S., and Garrett, K. A. 2008. Ecology and epidemiology in R: Disease progress over time. Plant Health Instructor. Published online. doi:10.1094/PHI-A-2008-0129-02

Taylor, A., Vágány, V., Jackson, A. C., Harrison, R. J., Rainoni, A., and Clarkson, J. P. 2016. Identification of pathogenicity-related genes in Fusarium oxysporum f. sp. cepae. Mol. Plant Pathol. 17:1032-1047.

Tesdall, G. R., Magdama, F. A., and Jimenez-Gasco, M. M. 2017. Towards sustainable solutions for Fusarium wilt: Ecology of putative pathogenicity factors in populations of Fusarium oxysporum from banana. Abstr. Phytopathology 107(S5.1):117.

Thatcher, L. F., Gardiner, D. M., Kazan, K., and Manners, J. M. 2012. A highly conserved effector in Fusarium oxysporum is required for full virulence on Arabidopsis. Mol. Plant-Microbe Interact. 25:180-190.

Tonukari, N. J., Scott-Craig, J. S., and Walton, J. D. 2000. The Cochliobolus carbonum SNF1 gene is required for cell wall-degrading enzyme expression and virulence on maize. Plant Cell 12:237-248.

United States Department of Agriculture Economic Research Service. 2007. Fresh-Market Spinach: Background Information and Statistics. USDA Economic Research Service, Washington, D.C. Published online. https://wayback.archive-it.org/5923/20120614073604/http://www.ers. usda.gov/News/spinachcoverage.htm

van Dam, P., de Sain, M., Ter Horst, A., van der Gragt, M., and Rep, M. 2018. Use of comparative genomics-based markers for discrimination of host specificity in Fusarium oxysporum. Appl. Environ. Microbiol. 84: e0186-17.

van Dam, P., Fokkens, L., Ayukawa, Y., van der Gragt, M., Ter Horst, A., Brankovics, B., Houterman, P. M., Arie, T., and Rep, M. 2017. A mobile pathogenicity chromosome in Fusarium oxysporum for infection of multiple cucurbit species. Sci. Rep. 7:9042. 
van Dam, P., Fokkens, L., Schmidt, S. M., Linmans, J. H., Kistler, H. C., Ma, L. J., and Rep, M. 2016. Effector profiles distinguish formae speciales of Fusarium oxysporum. Environ. Microbiol. 18:4087-4102.

van Esse, H. P., Van't Klooster, J. W., Bolton, M. D., Yadeta, K. A., van Baarlen, P., Boeren, S., Vervoort, J., de Wit, P. J. G. M., and Thomma, B. P. H. J. 2008. The Cladosporium fulvum virulence protein Avr2 inhibits host proteases required for basal defense. Plant Cell 20: 1948-1963.

Wickham, H., Averick, M., Bryan, J., Chang, W., McGowan, L. D., François, R., Grolemund, G., Hayes, A., Henry, L., Hester, J., Kuhn, M., Pedersen, T. L., Miller, E., Bache, S. M., Müller, K., Ooms, J., Robinson, D., Seidel, D. P., Spinu, V., Takahashi, K., Vaughan, D., Wilke, C., Woo, K., and Yutani, H. 2019. Welcome to the Tidyverse. J. Open Source Softw. 4: 1686.

Widinugraheni, S., Niño-Sánchez, J., van der Does, H. C., van Dam, P., García-Bastidas, F. A., Subandiyah, S., Meijer, H. J. G., Kistler, H. C.,
Kema, G. H. J., and Rep, M. 2018. A SIX1 homolog in Fusarium oxysporum f. sp. cubense tropical race 4 contributes to virulence towards Cavendish banana. PLoS One 13:e0205896.

Williams, A. H., Sharma, M., Thatcher, L. F., Azam, S., Hane, J. K., Sperschneider, J., Kidd, B. N., Anderson, J. P., Ghosh, R., Garg, G., Lichtenzveig, J., Kistler, H. C., Shea, T., Young, S., Buck, S. A., Kamphuis, L. G., Saxena, R., Pande, S., Ma, L. J., Varshney, R. K., and Singh, K. B. 2016. Comparative genomics and prediction of conditionally dispensable sequences in legume-infecting Fusarium oxysporum formae speciales facilitates identification of candidate effectors. BMC Genomics 17:191.

Zhang, C., Rabiee, M., Sayyari, E., and Mirarab, S. 2018. ASTRAL-III Polynomial time species tree reconstruction from partially resolved gene trees. BMC Bioinformatics 19:153.

Zhou, X. G., and Everts, K. L. 2007. Characterization of a regional population of Fusarium oxysporum f. sp. niveum by race, cross pathogenicity, and vegetative compatibility. Phytopathology 97:461-469. 